\title{
Catalyzing personal and social change around gender, sexuality, and HIV: Impact evaluation of Puntos de Encuentro's communication strategy in Nicaragua
}

Irela Solorzano

Amy Bank

Rodolfo Pena

Henry Espinoza

Mary Ellsberg

See next page for additional authors

Follow this and additional works at: https://knowledgecommons.popcouncil.org/departments_sbsr-hiv

Part of the Demography, Population, and Ecology Commons, Health Communication Commons, Health Policy Commons, Immune System Diseases Commons, International Public Health Commons, Medicine and Health Commons, Public Health Education and Promotion Commons, and the Virus Diseases Commons How does access to this work benefit you? Let us know!

\section{Recommended Citation}

Solorzano, Irela, Amy Bank, Rodolfo Pena, Henry Espinoza, Mary Ellsberg, and Julie Pulerwitz. 2008. "Catalyzing personal and social change around gender, sexuality, and HIV: Impact evaluation of Puntos de Encuentro's communication strategy in Nicaragua," Horizons Final Report. Washington, DC: Population Council. 


\section{Authors}

Irela Solorzano, Amy Bank, Rodolfo Pena, Henry Espinoza, Mary Ellsberg, and Julie Pulerwitz 


\section{Catalyzing Personal and Social Change}

Around Gender, Sexuality, and HIV: Impact Evaluation of Puntos de Encuentro's Communication Strategy in Nicaragua
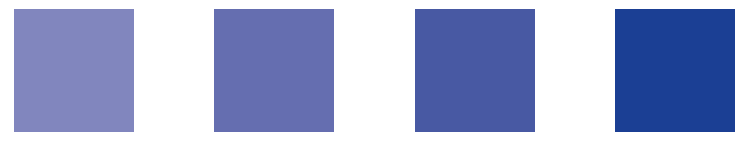

Puntos de Encuentro CIDS/UNAN León

PATH

Horizons Program 


\section{Catalyzing Personal and Social Change Around Gender, Sexuality, and HIV: Impact Evaluation of Puntos de Encuentro's Communication Strategy in Nicaragua}

Irela Solórzano and Amy Bank, Puntos de Encuentro Rodolfo Peña, CIDS/UNAN León

Henry Espinoza, Consultant

Mary Ellsberg, PATH

Julie Pulerwitz, Horizons Program/PATH

2008 


\section{Acknowledgments}

\section{Research coordination \\ Julie Pulerwitz, Horizons/PATH; Mary Ellsberg, PATH; Rodolfo Peña, National Autonomous University of Nicaragua (CIDS, UNAN-León); Henry Espinoza, independent; Irela Solórzano, Amy Bank, Humberto Abaunza (2002-3), and Jeaneth Corrales (2002-4), Puntos de Encuentro}

\section{Panel study and quantitative analyses}

Panel study: Rodolfo Peña, head researcher Statistical analysis: Rodolfo Peña, Bismark Rodríguez (CIDS), Teresa Somarriba García, Consuelo Flores Montalván, and Rafael Espinoza Montenegro (UNANLeón)

Step-wise model: Rodolfo Peña and Bismark Rodríguez

PAR analysis: Mary Ellsberg

Additional analysis: Sarah Bradshaw and Brian

Linneker (Progressio/Middlesex University)

\section{Qualitative studies}

Qualitative 1: Oswaldo Montoya

Qualitative 2: Camilo Antillón and Henry Espinoza

Qualitative 3: Almachiara D'Angelo and Patrick Welsh

\author{
Monitoring \\ Irela Solórzano, Jeaneth Corrales, Karime Ulloa, Olga \\ Rocha, Maria Belén Diaz \\ Research assistant \\ Olga Rocha
}

\section{Translation from Spanish}

Gareth Richards

\section{Project Donors (2002-2005)}

The following donor agencies supported, in big and small ways, the implementation and evaluation of SDSI 2002-2005: Royal Norwegian Embassy, Austrian Embassy, DFID (Great Britain), Royal Danish Embassy, Oxfam Novib (Netherlands), Ford Foundation (Mexico/NY), UNICEF (Nicaragua), Forum Syd (Sweden), Terre des Hommes (Germany), Progressio (Great Britain), The Summit Foundation (USA), The Moriah Fund (USA), Oxfam (Canada), Broederlijk Delen (Belgium), InterAmerican Development Bank, UNFPA (Nicaragua), Save the Children (Norway), British Embassy, Christian Aid (Great Britain), CCFD (France), PATH (USA), and Horizons Program/Population Council (USA)

Additional credits appear in Appendices 1 and 2.

The study was carried out by:

\section{Hgrizons}
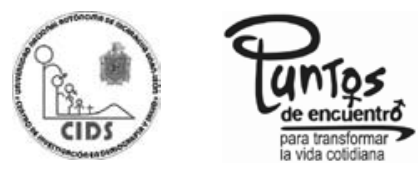

Additional support for the final report came from:

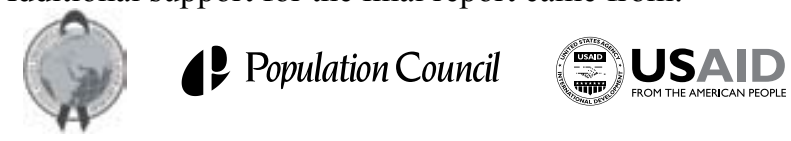

\footnotetext{
This final report was partially funded by the President's Emergency Plan for AIDS Relief and the generous support of the American people through the United States Agency for International Development (USAID) under the terms of Cooperative Agreement No. HRN-A-00-97-00012-00. The contents are the responsibility of the Horizons Program and do not necessarily reflect the views of USAID or the United States Government.

Published in June 2008. Copyright (C) 2008. The Population Council Inc.
}

Suggested citation: Solórzano, Irela, Amy Bank, Rodolfo Peña, Henry Espinoza, Mary Ellsberg, and Julie Pulerwitz. 2008. "Catalyzing individual and social change around gender, sexuality, and HIV: Impact evaluation of Puntos de Encuentro's communication strategy in Nicaragua," Horizons Final Report. Washington, DC: Population Council.

This document may be reproduced in whole or in part without permission of the Population Council provided full source citation is given and the reproduction is not for commercial purposes. 


\section{Table of Contents}

Executive Summary $\quad 1$

Introduction $\quad 3$

Context 3

The intervention and the evaluation 3

The study sites 4

The Intervention: "Somos Diferentes, Somos Iguales" 5

$\begin{array}{ll}\text { Conceptual Model } & 7\end{array}$

Methodology of the Impact Evaluation $\quad 11$

Quantitative component $\quad 11$

$\begin{array}{ll}\text { Qualitative component } & 17\end{array}$

Monitoring implementation $\quad 19$

Triangulation of results: Integration of quantitative and qualitative data 19

Results $\quad 20$

$\begin{array}{ll}\text { Characteristics of the sample } & 20\end{array}$

Perception of the social context 22

Scope and characteristics of exposure to SDSI 23

Impact of SDSI

Gender norms

$\begin{array}{ll}\text { Stigma } & 38\end{array}$

Knowledge and use of services $\quad 41$

Knowledge of HIV and risk perception $\quad 42$

Communication $\quad 45$

$\begin{array}{ll}\text { Self-efficacy } & 48\end{array}$

Condom use and other prevention behaviors $\quad 50$

Social capital and collective efficacy

More on Impact: Two Methods of Analysis Reveal SDSI's Impact $\quad 60$

SDSI's indirect relationship to condom use: A validation of SDSI's conceptual framework $\quad 60$

Entre amigas: An example of analysis of the synergistic and net impact of Sexto Sentido 64 in 10-14 year old girls 
Discussion and Reflections about the Results and Their Implications

Large-scale impact

Impact on complex processes

Gender, age, and the passage of time

The relative lack of use of health and social services

Prevention as maintenance over time

The importance of interpersonal communication

The question of "pre-disposition" and/or "self-selection"

Reaching and impacting different groups within the adolescent and youth population

Cost-effectiveness of SDSI

Reflections on the Study's Methodology

Rigor and reliability

The Hawthorne effect

Methodological challenges and the need for many different approaches 


\section{Executive Summary}

Somos Diferentes, Somos Iguales (SDSI) ${ }^{1}$ is a communication for social change strategy that aims to prevent future HIV infections in Nicaragua by means of mass communication actions, including entertainment-education (edutainment) programs; local capacity building; and the development of links, coordination, and alliances within communities.

This report presents the results of the SDSI impact study, an inter-institutional evaluation that included collaboration from PATH, the Horizons Program/Population Council, the National Autonomous University of Nicaragua's (UNAN-León's) Center for Demographic and Health Research (CIDS), independent consultants, and Puntos de Encuentro, a Nicaraguan NGO. The purpose of the evaluation was to explore the intervention's impact on a representative group of young people, on collective processes, and on the local environment. In particular, it measured SDSI's impact on the following areas: gender equity, stigma reduction, personalization of risk perception, knowledge and use of services, interpersonal communication, HIV prevention practices, and personal and collective efficacy for HIV prevention.

In Nicaragua's national context of low HIV prevalence, the country's current challenge is prevention of future infections. SDSI was implemented from 2002-2005 and focused on addressing social and cultural issues that hinder HIV prevention. The project's intervention activities were designed to mutually reinforce each other and included: a national "social soap" TV series; a nightly youth talk call-in radio show; development and distribution of methodological materials for use by local groups; and various community-based activities such as training workshops for young people involved in communications work, youth leadership camp, and coordination with local non-profits and health and social service providers. The weekly TV drama Sexto Sentido was the strategy's largest component, broadcast not only in Nicaragua but also in Costa Rica, Guatemala, Honduras, Mexico, and the US. ${ }^{2}$

The SDSI evaluation was conducted using both quantitative and qualitative survey instruments. Evaluation of SDSI included household surveys, as well as in-depth interviews and focus group discussions with participants, non-participants, and key stakeholders. A longitudinal panel study was used to quantitatively evaluate SDSI's impact in individuals. The study consisted of three surveys, administered in October 2003, 2004, and 2005 to the same group of young people, whose ages ranged from 13 to 24 years in 2003. The surveys were implemented in three Nicaraguan cities: Estelí, Juigalpa, and León. ${ }^{3}$

The results of the evaluation reveal that exposure to the SDSI project was widespread. At the end of the intervention, nine out of every ten people interviewed were familiar with at least one of the mass communication components. Sexto Sentido TV was widely watched on a regular basis by a large part of the adolescent and youth population, with 59 percent of the sample corresponding to the category of "greater exposure" (people who watched at least two of the three previous seasons of Sexto Sentido TV

\footnotetext{
${ }^{1}$ Somos Diferentes, Somos Iguales translates as "We are Different, We are Equal."

${ }^{2}$ This evaluation only studied impact in Nicaragua.

${ }^{3}$ A companion descriptive report, entitled Expectations and Realities: Nicaraguan youth navigate gender, sexuality, HIV, and more, summarizes some of the most compelling patterns that emerge from the data collected between 2003 and 2005. Disaggregated by gender, age, and location, the data provide a complex portrait of the sexual and reproductive realities among Nicaraguan youth. Available in English at www.puntos.org.ni/english.
} 
"almost always" or "occasionally"). Additionally, the proportion of people who had heard the Sexto Sentido radio program increased substantially over time, from 9 percent in 2003 to 29 percent in 2005. The survey findings indicate that greater exposure to SDSI led to positive changes on a population level. The intervention resulted in a significant reduction of stigmatizing and gender-inequitable attitudes, an increase in knowledge and use of HIV-related services, and a significant increase in interpersonal communication about HIV prevention and sexual behavior. Qualitative findings indicate that SDSI played an important role in promoting community-based dialogue on key topics, strengthened youth leadership, and fostered alliances between organizations.

The data suggest that greater exposure to SDSI has positive effects on interpersonal communication, which in turn helps people perceive their own personal risk of contracting HIV, and provides greater capacity for individuals to address the issue of prevention with their partners. Partner communication about HIV prevention is directly and positively correlated with consistent condom use. The evaluation suggests that the indirect effects of SDSI on condom use are strong and positive, at the same time there was also a direct association between SDSI and condom use with casual partners.

The impact evaluation demonstrates that the SDSI strategy has made a large-scale contribution in key aspects of HIV prevention. In addition to individual behavior changes directly associated with greater exposure to SDSI and societal-level changes identified in the evaluation's qualitative studies, the results validate the conceptual framework of both the intervention and the evaluation. The results suggest that individual behaviors (e.g., consistent condom use in sexual relations) are not isolated from the environment in which people live, but rather are related to social contexts and processes.

Very few studies in the field of social communication have been as rigorously implemented as this impact evaluation. In this sense, the study's results represent an important contribution to international literature on the effectiveness of this kind of program. The results of this study provide an opportunity to explore and reflect on the methodologies used to evaluate communication for social change, improve the design and implementation of prevention programs, analyze issues and concerns related to societal and individual behavior change, and analyze the potential for integrating edutainment and social mobilization with HIV prevention. 


\section{Introduction}

\section{Context}

HIV infection rates in Nicaragua are low, but have trended upward over the past two decades. Between 1987 and 2002 the Nicaraguan Ministry of Health reported 1,081 positive cases of HIV (National AIDS Program 2003). By the end of 2006, 2,433 cases had been reported, 94 percent of which resulted from sexual contact (National STI/HIV Program). Between 1998 and 2003, the HIV incidence rate in Nicaragua tripled, from 1.3 to 3.9 infected individuals per 100,000 inhabitants. By 2006, this rate had more than doubled, to 7.1 per 100,000 inhabitants. The current prevalence of HIV infection among $15-49$ year-olds is estimated at 0.2 percent, and the virus is mainly propagated by sexual contact.

The major challenge in this context of low HIV prevalence is the prevention of future cases. This is particularly true in light of the fact that, while Nicaragua's low HIV rates are encouraging, the country's current economic and sociocultural conditions render it particularly vulnerable to future spread of the disease. These conditions include increasing levels of poverty and migration, as well as the fact that the epidemic has become generalized in neighboring Honduras and Guatemala. As Peter Piot, who heads the Joint United Nations Program on HIV (UNAIDS) commented in 2006, "When I look at Latin America, I think Central America is the most vulnerable for the spread of HIV" (Cohen 2006).

Many factors contribute to Nicaragua's vulnerability to future spread of HIV. War and political unrest kept Nicaragua politically and economically isolated during the 1980s and into the 1990s. In addition, cultural and social norms based around "machismo" and constructions of gender and sexuality have historically promoted unsafe sexual practices, such as multiple sexual partners among men and a lack of negotiating capacity among women. Other problems include the limited availability of information and effective education on sexuality, as well as norms that discourage the provision of such education to young people. Nicaragua also suffers from limited availability of testing and treatment services, reducing the probability of early detection and care.

HIV prevention requires educating individuals about risky behavior, fighting against HIV-related stigma and discrimination, and fostering a sociocultural environment conducive to safer sexual practices. This in turn requires addressing - and critically analyzing - the social norms that regulate sexuality, especially gender-based norms.

\section{The Intervention and the Evaluation}

The SDSI project was implemented from 2002 to 2005 as part of an ongoing communication strategy for social change that aims to prevent the epidemic's expansion in Nicaragua by means of mass communication actions; interpersonal processes to strengthen local capacities; and the development of links, coordination, and alliances among national and local groups that work with youth and/or sexual and reproductive health and rights. 
This document presents the results of the SDSI impact study, an inter-institutional evaluation that included collaboration from PATH, the Population Council's Horizons Program, the National Autonomous University of Nicaragua's (UNAN-León's) Center for Demographic and Health Research (CIDS), independent consultants, and Puntos de Encuentro, a Nicaraguan NGO. The purpose of the evaluation was to explore the project's impact on a representative group of young people, on collective processes, and on the local environment. It aimed to do so in the following areas: stigma reduction, gender equity, the right of young people to live without discrimination and violence, and personal and collective efficacy for HIV prevention.

\section{The Study Sites}

The research sites for the study were selected to include areas with differing social qualities, including differing levels of community HIV activities and varying institutional capacity of the local organizations. Sites also aimed to represent differing levels of local organizational collaboration with Puntos de Encuentro and differing intensity of SDSI implementation of non-mass media activities (such as workshops).

Based on these criteria, the quantitative study was implemented in the urban areas of three of the country's municipal capitals: Estelí and León, in the departments the same respective names; and Juigalpa in the department of Chontales. Estelí is located in the country's northern region, León is in the Pacific region, and Juigalpa is located in Nicaragua's central region. (León has the largest population of the three study cities and is the second largest city in the country in terms of population.)

The qualitative studies included the three cities named above, along with the city of Bilwi (also known as Puerto Cabezas) in the North Atlantic Autonomous Region. The population of Bilwi is multiethnic, multicultural, and multilingual, and the town is much smaller and poorer than the other three cities studied.

At the beginning of the quantitative study, Estelí and León were identified as having high levels of community activity, a strong social fabric comprised of numerous long-standing organizations, intense SDSI work, and a high level of alliances. Juigalpa, on the other hand, was identified as having lower levels of these characteristics. Estelí has the most organizations and centers providing services to adolescents and young people, while Juigalpa has the least. Juigalpa is also the most socially and politically conservative of the three sites.

Generally speaking, the sites selected are in municipalities with a mainly urban population; nationally, Nicaragua's population is 56 percent urban, a third of which consists of 10-24 year-olds (Nicaraguan Statistics and Census Institute 2006). While Chontales has the highest illiteracy rate (28 percent) of the three departments included in the study, illiteracy rates in Estelí and León are also significant (19 percent and 16 percent, respectively). The three cities have relatively similar rates of teen pregnancy and STIs: Between a fifth and a quarter of 15-19 year-old women in the three departments have been pregnant at least once, and STI prevalence among 15-49 year-old women ranges from 10 percent to 17 percent (Nicaraguan Statistics and Census Institute 2002). 


\section{The Intervention: "Somos Diferentes, Somos Iguales"}

Puntos de Encuentro, a feminist Nicaraguan NGO that works with women's and youth groups to promote human rights, initiated SDSI in 2000 to coordinate its complementary media, capacitybuilding, and networking activities. The 2002-2005 project evaluated in this report constituted the second phase of the overall SDSI strategy. The overall objective of the project was to promote young people's rights and individual and collective empowerment, especially in relation to sexual and reproductive health and rights issues. These issues include HIV, gender-based violence, emergency contraception, and substance abuse/addiction.

A self-defined "progressive social change" organization, Puntos de Encuentro designed the project to combine individual and social change catalysts that operate simultaneously and over time. The project design utilizes the reach and legitimacy of mass media "edutainment" programs, reinforced by capacity building with grassroots youth leaders and communicators, network building, and local-level mobilization. The project's main components are:

- Sexto Sentido, a weekly "social soap" TV series broadcast on national commercial and local cable stations. The series integrates various issue-based storylines and has successfully introduced sensitive and complicated topics such as sexuality into the home.

- Sexto Sentido Radio, a live nightly radio call-in show broadcast simultaneously on a national FM radio station and nine local radio stations. The call-in shows discuss and debate the issues touched on in the TV series.

- Youth leadership training and capacity building with grassroots youth leaders and communicators, aimed at strengthening analytical and leadership skills related to sexual and reproductive health and rights issues. These skills particularly focus on gender, stigma, discrimination, and genderbased violence. A major component of the work is the promotion of alliances across different groups, including between young people and the adult leaders of their organizations, to promote more effective youth involvement. (Several of the capacity-building activities include the participation of adults.)

- Participation in and coordination with national and local youth, as well as with coalitions concerned with sexual and reproductive rights, human rights, women's issues, and anti-violence.

- Coordination with national and local journalists and media outlets and in particular with young communicators.

- Development and distribution of support materials, resource packs, and thematic campaigns.

- Coordination with youth organizations and leaders in other Central American countries, as a way to expand the project regionally.

- Ongoing monitoring and evaluation activities. In the case of this project, the operations research evaluation was carried out in conjunction with the Horizons Program, PATH, the Center of the Study of Demographics at the University of Leon, and independent researchers.

The project's second phase (implemented from 2002-05) included a special focus on HIV prevention within the context of young people's sexuality, gender norms, risk perception, and decision making. The "machismo as a risk factor" approach was central to the project's work with adolescents and young people. 
This work included a multi-media campaign and a series of regional workshops developed under the slogan, "We need to be able to talk." The idea was to point out the power of speaking about taboo subjects and the importance of social support in the process of creating change. The campaign included the production and distribution of special editions of the Sexto Sentido television series, which centered on HIV and sexual abuse. It also included methodological guides for workshops and training courses for local activists as well as agreements with local health and social service providers. Billboards in 17 cities publicized the slogan, Sexto Sentido TV and Radio, and identified health service providers in each locality. Local organizations distributed educational pamphlets and flyers. These materials were also distributed during cast tours to schools and community centers, during which Sexto Sentido cast members led discussions on HIV and sexual abuse.

This phase also included a joint effort with the PATH-sponsored "Entre Amigas" project, an innovative multi-level program dealing with sexual and reproductive health issues relevant to 10-14 year-old girls - a particularly underserved population. 


\section{Conceptual Model}

HIV-related stigma, discrimination, and denial remain among the most poorly understood aspects of the HIV epidemic and some of the biggest barriers to successful HIV programs. The United Nations Commitment Declaration on AIDS identifies stigma, discrimination, and denial (SDD) as an essential element to be targeted in the global response to the HIV/AIDS pandemic challenge (Declaration of Commitment 2001). SDD is often directed at people living with HIV as well as individuals and groups associated in some way with the disease - such as sex workers and gay men. SDD inhibits both HIV prevention as well as efforts to provide treatment, care, and support.

From the prevention perspective, refusal to use condoms may stem from a lack of HIV risk perception or from concerns about raising the issue of disease risk by requesting condom use. Fear of stigma or discrimination, as well as risk denial, can lead to reluctance to seek HIV counseling, testing, and even available treatment and support (Malcolm et al. 1998). Even though awareness of the issue's importance has existed since the pandemic began, there has been limited evidence of successful interventions to date. A literature review of interventions that address HIV-related stigma found 21 published evaluations worldwide, including just one national multimedia campaign (Brown et al. 2001). The relative paucity of successful stigma-reduction strategies highlights the need for improved understanding of how SDD functions, and suggests that new attempts must be developed and evaluated to understand the potential use of SDD-reduction as an HIV-risk reduction strategy.

HIV-related stigma refers to negative beliefs and attitudes toward people with — or associated withHIV (e.g., a belief that people with HIV should be avoided or are to blame for their illness). HIVrelated discrimination refers to behaviors resulting from stigmatizing views (e.g., being fired from a job because of HIV status). In this respect, discrimination has also been called "enacted stigma." HIVrelated denial, meanwhile, refers to the reluctance of an individual or society to perceive the risk of HIV. ${ }^{4}$ HIV-related SDD stems from both fear of contagion and disease, and the blame associated with engaging in what are many cultures deem "immoral" or "bad" behaviors, such as pre-marital sexual activity among women.

These non-normative behaviors are also typically associated with certain already marginalized groups, such as sex workers and gay men. HIV-related SDD is therefore inextricably linked to stigmas associated with sexuality and gender, and is often compounded by stigmas associated with race and poverty. Stigma toward what some have called "high risk groups"-particularly men who have sex with men and sex workers - creates an environment in which people who engage in high-risk behavior but do not identify with these groups fail to realize they are at risk of infection and therefore often fail to engage in safe sexual practices.

Successfully addressing HIV-related SDD requires addressing the multiple sources of HIV-related stigma, including associations with sexuality and gender. For example, if women who are sexually active before marriage or have multiple sexual partners experience stigma because of inequitable gender norms, women will avoid seeking information on sexual health and disease prevention so as not to suggest that they are sexually active or have various partners. Similarly, as long as homophobia

${ }^{4}$ Denial is closely linked to stigma and discrimination but in this paper it differs in that it has a more psychological focus, while stigma and discrimination have a more societal focus. 
is rampant, men who have sex with men will continue be clandestine about it and may engage in unsafe sexual practices with the men and/or women with whom they are involved. married men who have sex outside of marriage may not use condoms with their wives because they know it would suggest they are indeed having extramarital sex. Reviews of studies on reproductive and sexual health, including HIV prevention, indicate the effectiveness of strategies that use "entertainment-education" (edutainment) - particularly radio and TV soaps — in combination with community mobilization and the promotion of social support networks (Singhal and Rogers 1999). By tying together various storylines and themes, edutainment radio and TV soaps are able to address a variety of issues in complex and integrated ways.

The format allows intimate topics such as sexuality to be introduced into the home efficiently, and in a culturally sensitive way. It also promotes identification with characters and storylines, which can impress upon viewers the consequences of different attitudes and actions. These "parasocial" relationships between viewers and characters promote self-efficacy, and can instill viewers with confidence in their ability to enact behaviors they have seen modeled by fictional characters. This can be applied to both HIV prevention behaviors as well as stigma-reduction.

Studies have found that knowing someone with HIV or AIDS who talks openly about the subject is associated with reduced HIV stigma (Green et al., 2006). Including an HIV-positive character in a soap opera or having an HIV-positive person share his or her experiences on a radio show can create a parasocial relationship that acts as a substitute for actually knowing such a person. These formats also allow repeated exposure to different aspects of the same issue over a prolonged period of time.

In addition, soap opera and radio show formats promote discussion of the show's topics among viewers/listeners and their social networks, including family, friends, and sexual partners. This is particularly important given the existing evidence that social cohesion and the diffusion of information on HIV is an important factor in the substantial reduction of HIV prevalence. Evidence from Uganda, for example, suggests that personal networks are more effective than health "experts" in reducing HIV prevalence (Stoneburner et al. 2000).

The SDSI strategy draws on Bandura's social cognitive theory (SCT) (Bandura 1977) and theoretical views of communication for social change as a process of dialogue through which people define who they are, what they desire, and how they can obtain their goals (Gray-Felder and Dean 1999). In SCT, human behavior results from the interaction of behaviors, personal factors (including thoughts and perceptions), and environmental influences. SCT assumes there is a dynamic and reciprocal interaction between an individual, the individual's behavior, and the environment in which the behavior is performed.

SCT is the most common theoretical perspective underlying drama- or entertainment/education-based interventions, because of its focus on social modeling. The strategy promotes behavior change by having characters with which viewers are able to relate practice the kinds of attitudes and behaviors the intervention is promoting. A meta-analysis of 12 HIV risk-reduction interventions that used SCT in controlled experimental trials found that all achieved positive changes in reducing risk behavior, with a moderate effect size that met or exceeded the effects of other theory-based behavioral change interventions (Greenberg 1996). 
One of SCT's central tenets is self-efficacy, or confidence in one's ability to enact a certain behavior (Bandura 1986). More recently, the concept of collective efficacy has received significant attention. Collective efficacy can be defined as the degree to which individuals in a system believe they can organize and execute courses of action required to achieve collective goals. Research on entertainment education interventions suggests that while media-stimulated change contains paradoxes and contradictions, key elements within this process include parasocial interaction, peer communication, and collective efficacy (Papa et al. 2000).

Previous reproductive health studies have found that reinforcing the entertainment-education model with community mobilization and the promotion of social support networks is particularly promising. Taken together, these strategies can influence the collective processes that lead to-and preserveinequity in everyday social relations. In this respect, strategic communication programs need to be designed within a broader framework of social, political, and cultural processes.

Social change is related to various processes: the participation and commitment assumed by social actors; strengthening interpersonal and institutional support networks; creating or reinforcing individual and collective capacities; and ensuring favorable conditions for open dialogue and debate on issues related to sexuality and gender relations. Dialogue and collective action can, in turn, transcend the individual level and enable social change through various means: the improvement of skills needed to achieve new behaviors; changes of knowledge, values, perceived risks, subjective norms, and self-image; responses based on solidarity, empathy, and trust; and increased trust and support within communities. In addition, dialogue and collective action influence individuals' intentions to assume both new and specific behaviors in the future (Figueroa et al. 2002).

Collective efficacy can be assessed on the basis of group confidence in collective decision making and actions, perception of the talents and capacities of other group members to that end, and perceived confidence that members of the group are capable of meeting their individual responsibilities. In addition to leadership, other proposed change indicators for evaluating the results of communication for social change include the degree and equity of participation, equity of information, sense of ownership (appropriation), social cohesion, and social norms.

The SDSI conceptual model incorporates both the importance of influencing individual knowledge, attitudes, and norms as well as the larger social context, in order to affect large-scale social change that enables individual behavior change among young people in Nicaragua and the Central American region (see Figure 1). 
Figure 1 SDSI Conceptual Model 2002-2005: Fostering a more enabling environment for HIV prevention

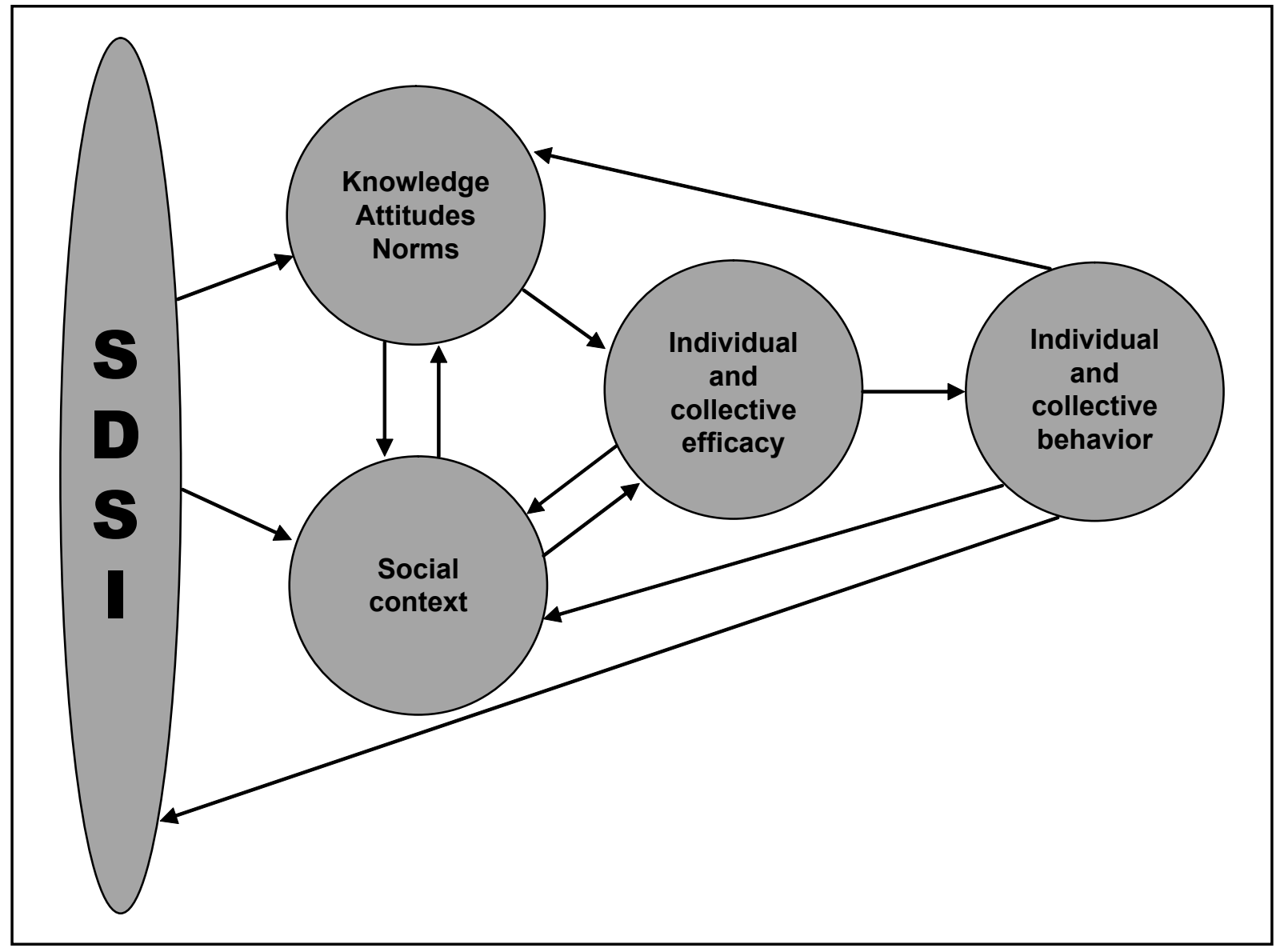

The model proposes dynamic relationships among four major spheres: 1) individuals' gender knowledge, attitudes, and norms; 2) the social context; 3) individual and collective efficacy; and 4) individual and collective behaviors. The SDSI impact study focused on analyzing these spheres in relation to HIV prevention, the exercising of responsible sexuality, and the prevention of gender-based violence.

For the purposes of the study, the sphere of knowledge, attitudes, and norms comprised individual knowledge, attitudes, and behaviors related to sexual life, partner negotiation, and HIV risk and prevention; attitudes and practices related to violence, including sexual abuse; and social attitudes and norms regarding gender roles and relations, sexuality, and HIV-related discrimination and stigma.

The social context was studied in terms of perception of the social environment, as well as links with networks or support structures identified on the community level. Self-efficacy was analyzed with respect to interpersonal communication, particularly with respect to communication and negotiation with sexual partners regarding HIV prevention. Collective efficacy was analyzed on the local level and within the participants' generational group. 


\section{Methodology of the Impact Evaluation}

The impact evaluation of SDSI included several studies in the framework of a quantitative-qualitative approach. The information generated by the studies and implementation monitoring was compared using an integrated methodology based around the objectives of the SDSI project. An interinstitutional team then analyzed and interpreted the data.

\section{Quantitative Component}

A longitudinal panel study was used to quantitatively evaluate SDSI's impact in individuals. The study consisted of three surveys, administered in October 2003, 2004, and 2005 to the same group of young people, whose ages ranged from 13 to 24 years in 2003. The surveys were implemented in Estelí, Juigalpa, and León, three Nicaraguan cities selected according to a series of criteria intended to incorporate varying qualities of the social fabric, community anti-AIDS actions, and previous work with SDSI. Compared to Estelí and León, there was less alliance-based work and less presence of SDSI in Juigalpa.

\section{Sample}

The sample is representative of the population groups studied in each of the three cities. The sampling was done by clusters and in several stages. The clusters were selected by blocks in each city and the participants were then selected from within each block.

The sample is urban and was estimated at 4,800 participants, with 1,600 individuals ( 800 men and 800 women) from each of the three research sites. The inputs used for the calculations included a maximum probability of 50 percent $(0.50)$ for change or non-change in behaviors and attitudes and an 80 percent power to detect that change. The calculation of the sample also has a reliability level of 95 percent. In other words, each time we observed a result, that result would be correct for 95 out of every 100 observations. As the sample selection procedure was to be based on the cluster definition and selection technique, the sample was multiplied by 1.5 to give the necessary sample size in order to correct for any errors caused by the use of cluster sampling. An extra 32 percent was then added to cover those individuals who could not be located from one survey to the next (also known as "lost to follow up.")

\section{Identification and follow up}

For the identification and follow up of the participants, geo-referenced maps were constructed for each of the three cities involved in the study. First, digital and/or non-digital maps were located for each selected city or departmental capital (urban areas) and these maps were then fed into the Arc-View computer program. This software made it possible to geo-reference the maps and the data obtained from the sample calculation and the baseline survey. 
Once the maps had been geo-referenced in the Arc-View program, neighborhoods, blocks, and houses were delimited and counted. The number of individuals between the ages of 13 and 24 years per household was then estimated; neighborhoods, blocks, and houses were selected and coded. This was a fundamental step for following up on the selected participants over time and controlling the quality of the information obtained.

\section{Response rate, loss to follow up, and "survivors"}

A very large proportion of people agreed to participate in the study and there was an acceptable level of loss to follow up over the course of the evaluation. A total of 4,567 people agreed to be included in the first (baseline) survey in 2003, representing a 95 percent positive response. The total loss to follow up in relation to the initial sample was 35 percent, which is very close to the loss anticipated when the sample was being calculated ( 32 percent). The final analysis to measure the impact of SDSI is based on the sample of "survivors," a term used to describe the 3,099 people who participated in all three surveys and whose responses were used to analyze impact. ${ }^{5}$

Comparisons between the total samples and the "survivor" sample were carried out to determine if there were different tendencies or characteristics between the two samples. The tendencies and characteristics were the same. For example, there were no differences in the percentage of respondents who listened to the SDSI radio programs when comparing the total samples from each round (9 percent, 19 percent, and 29 percent) with data reported by the survivors ( 9 percent, 18 percent, and 29 percent). Table 1 shows other variables that were observed.

\footnotetext{
${ }^{5}$ In fact, the total "survivor" sample was 3,137, but for technical reasons only 3,099 responses were able to be used in the analysis.
} 
Table 1 Comparative chart of total samples and "survivors"

\begin{tabular}{|c|c|c|c|}
\hline & $\begin{array}{c}2003 \\
\%\end{array}$ & $\begin{array}{c}2004 \\
\%\end{array}$ & $\begin{array}{c}2005 \\
\%\end{array}$ \\
\hline \multicolumn{4}{|l|}{ Has children } \\
\hline Survivors* & 15 & 21 & 24 \\
\hline Total $^{* *}$ & 17 & 22 & 25 \\
\hline \multicolumn{4}{|l|}{ Studies } \\
\hline Survivors* & 70 & 63 & 58 \\
\hline Total $^{* *}$ & 66 & 60 & 57 \\
\hline \multicolumn{4}{|c|}{ Belongs to some group or organization } \\
\hline Survivors* & 19 & 22 & 17 \\
\hline Total $^{\star *}$ & 19 & 21 & 17 \\
\hline \multicolumn{4}{|c|}{$\begin{array}{l}\text { Women with condoms in their purses are easy } \\
\text { (correctly answered "no") }\end{array}$} \\
\hline Survivors* & 48 & 53 & 64 \\
\hline Total $^{* *}$ & 47 & 54 & 64 \\
\hline \multicolumn{4}{|c|}{ Listens to SDSI radio } \\
\hline Survivors* & 9 & 18 & 29 \\
\hline Total ${ }^{* *}$ & 9 & 19 & 29 \\
\hline
\end{tabular}

*Survivors $=3,099$ participants in all three surveys whose responses are used to analyze impact over time.

** Total per survey round $=4,567$ in the 1 st; 3,682 in the 2 nd; and 3,366 in the 3 rd.

Two different questionnaires were used to gather information during each round:

- The first was applied by the survey personnel and contained the following sections: sociodemographic aspects; perception of the environment; attitudes about gender norms and gender-based violence; sexual and reproductive health, including HIV; attitudes toward HIV prevention, and individual and collective efficacy to that end; discrimination and racism in Nicaragua; and general exposure to the communication media and SDSI.

- The second was an easy-to-read written questionnaire that each participant completed on his or her own and then placed in an envelope (participants could request help filling out the form if they needed it). This questionnaire explored the most sensitive aspects of sexuality and HIV prevention, such as having undergone an HIV test or interest in doing so, sexual practices, condom use, and history of sexual abuse.

The instruments were piloted and validated and each survey was supervised in each of the three cities. Interviewers and participants were paired off by sex, with women interviewing women and men interviewing men. Generally speaking, the interviews took place within the home of the participant, and lasted about an hour. 


\section{Ethical aspects}

The participants' informed consent was obtained prior to the interview. The research team ensured that at the beginning of the study and during each survey all of the participants understood: a) the importance and nature of their participation; b) who to contact to clear up any doubts about the study; c) the need to be visited again; d) that they consented to participate in the study; and e) that they had the option of dropping out at any time. At the end of the interview, the participants were given materials with information on the different topics involved. During the third survey, they were also given information on local centers where they could receive services related to health and violence.

\section{Data analysis}

The panel study was implemented by the National Autonomous University of Nicaragua's (UNAN-León's) Center for Demographic and Health Research (CIDS), with support from PATH, the Population Council's Horizons Program, and independent consultants. Two complementary statistical analysis teams were organized. The first evaluated the effects of exposure to SDSI based on sociodemographic factors. The other team explored exposure effects and their relation to previous attitudes identified in the baseline to identify how those attitudes might have predisposed people to SDSI exposure or behavior change. Both cases involved the construction of a variable for approximation to SDSI exposure, based on exposure to the television program, and a set of principlerelated indices. The different steps involved in the analysis are described below.

\section{Univariate and bivariate analyses and longitudinal multivariate models}

The overall analysis included a number of different stages. The first analysis was carried out immediately after the first survey (baseline), providing a profile of the participants' initial situation.

The second stage of analysis was carried out immediately after the second survey, comparing the results to the baseline. Relevant results were further explored in the second qualitative study. The aspects explored were related to the local social context, gender norms, HIV-related stigma, knowledge about HIV and perception of the risk of infection, knowledge of and use of available services, exposure to the media, and exposure to SDSI.

Tendencies among the data from the three measurement groups started to be observed following the results of the third survey, and longitudinal variables were constructed, allowing the changes to be individually assessed. The follow up of the cohort of adolescents and young people generated data for biological variables that did not change over time (e.g., sex), for variables that did change over time in a single direction (e.g., increased age), and for sociodemographic variables and opinion responses that changed in multiple directions (e.g., perception of risk, attitudes, intimate partner status, level of education, interest in taking an HIV test). There were two principal types of result variables: dichotomous categorical variables (two responses: yes or no; agree or disagree) and numerical continuous variables (e.g., age, indices with various ranges of values).

To evaluate the data's internal validity, a series of tests was applied to key variables. For example, the reliability and internal consistency of the indices created were evaluated using Cronbach's Alpha test 
and factor analysis. In the case of sensitive responses related to sexuality and HIV, the reproducibility of the responses over time and in both kinds of questionnaires was evaluated by calculating the Kappa statistical value and the Pearson correlation factor.

Evaluating the association between the changes observed and exposure to SDSI involved constructing multivariate longitudinal models and exploring the interaction among variables. These models were adjusted to control the effect of sociodemographic variables, which are particularly affected by timedependent changes (e.g., age, education, marital status), as well as the effect of the sex and locality variables. The statistical tests employed depended on whether the variable being evaluated was continuous or categorical.

In the case of the indices, linear models were applied (general linear model) for repeated measurements with estimated marginal means tests, while logistical regression models such as generalized estimating equations (GEEs) were used for dichotomous categorical variables (e.g., condom use). It is important to point out that the significance level considered in the study is $p=0.05$, meaning that any association with a probability of over 0.05 (e.g., 0.15 ) is considered not statistically significant. Meanwhile, a 95 percent confidence interval was used in relation to the logistic regression models, meaning that the resulting Odds Ratios would lie within the defined range 95 out of every 100 times. Significance is inferred when the range of the confidence interval does not include 1.0. In the results section, Odds ratios are presented with their corresponding 95\% Confidence Intervals (95\% CI).

Each test attempted to rule out the possibility that the differences detected were due to causal relationships among variables. The methods used identified and controlled the confounding effects of other sociodemographic variables that could have been associated with prolonged exposure to SDSI (e.g., age, education). In this way, it was possible to determine if there really was a causal relationship between SDSI and the impact variables (e.g., indices). But the analysis also enabled us to identify and individually view the effect of the other variables, such as age and sex, if they did contribute to the result. The study design also controlled for possible effects of the interaction of independent variables (exposure, age, sex) on impact variables.

\section{Measurements using indices}

The intervention's impact was partially measured through the creation of indices. Several questions were grouped around one concept or impact indicator to form a single index. This allowed for the capture of a more global understanding of a given index concept, and complemented the results obtained from individual measurements.

Each question among the indices' different items required the participant to express a position of agreement, disagreement, or neither. The answers to each of the items were added to provide a value for the index, which could then be processed as a single variable. The indices' internal consistencies were statistically evaluated using Cronbach's Alpha test. The neutral answers were re-coded and treated as unwanted answers. The average value of responses was assigned to any item with a nonresponse. 
During the analysis, indices were constructed for gender norms, HIV-related stigma, social capital, self-efficacy, collective efficacy, and relationship power. To measure attitudes toward gender norms related to HIV prevention, sexual violence, and couple relationships, items were selected from the Gender Equitable Men (GEM) scale, which was developed and validated in Brazil (Pulerwitz and Barker 2007).

Meanwhile, questions derived from the recommendations formulated by the Interagency Stigma Indicators Working Group (Nyblade and MacQuarrie 2006) were used to measure HIV-related stigma. In the case of the indices for measuring social capital and efficacy, the evaluation team formulated items based on generally accepted rules for this type of question. Finally, a series of items from the Sexual Relationship Power Scale's control sub-scale were used to measure "relationship power" (Pulerwitz, Gortmaker, and DeJong 2000).

\section{Other analyses}

SDSI's preventative influence that can be attributed to the population was calculated for a subset of result variables using the following formula:

\section{$P A R=[($ percent of people exposed to SDSI among the positive cases) $x$ (Odds Ratio-1)]/Odds Ratio}

This analysis permits calculating the number of people with a certain response that could be attributable directly to impact of the intervention; in other words, it calculates the number of people that would have had different responses if SDSI had not been implemented. Based on this calculation, absolute numbers were projected with respect to the youth population of the study sites and then projected more broadly based on the national urban youth population.

The conceptual models were collectively constructed by taking into consideration the exposure variable, potential confounding variables (used to adjust the model), and dependent, or impact variables. The statistical approach was based on stepwise logistical regression for dichotomous dependent variables (e.g., condom use during the most recent sexual relations with a steady partner). The results were presented in crude and adjusted odds ratios (OR), and a 95 percent confidence interval $(\mathrm{CI})$ was used evaluate the level of statistical significance.

\section{Exposure to SDSI}

Intensity of exposure to Sexto Sentido TV was taken as the measure of approximation to exposure to SDSI. This design was based on the numerical robustness and detail of the information on television, which allowed for the definition of groups with varying degrees of exposure. Groups exposed to other components of SDSI were also evaluated, but the results corresponding to those groups' characteristics were similar to those related to television, so it was considered appropriate to use exposure to Sexto Sentido TV as the variable for exposure to SDSI. In addition, the intervention's massive scope made it impossible to identify a robust group of people "not exposed" to SDSI or Sexto Sentido TV, so the comparison was based on "more" or "less" exposure. That definition is described below. 
Reliability of the responses to sensitive issues

The validity of the sensitive responses was evaluated by measuring the reliability with which the same answer could be given to the same question formulated in different instruments or at different moments. The Kappa index test, or statistical Kappa, was used to evaluate the reproduction of responses to sensitive questions included in both the questionnaire applied by the interviewer and the one filled out by the participants themselves. For example, the question, "Have you had sexual relations?" was asked face-to-face by the interviewer and also appeared in the questionnaire filled out by the participants. The results showed a 93 percent agreement of answers, giving a Kappa value of exactly 0.93 , which is above 0.80 and therefore statistically significant $(\mathrm{p}<.001)$. Reproducibility of answers given at different moments was also evaluated through the question, "How old were you when you had your first sexual relations?" The correlation between answers given in the second and third surveys was evaluated using Pearson's chi-squared test, appropriate for measuring continuous variables. The correlation was 0.918 , which is very close to a perfect correlation of 1.000 . This means there was a 91 percent probability that people who said in the third survey that they had their first sexual relations at the age of 13 mentioned the same age in the previous survey.

The consistency was not as high for other questions, however, as in the case of responses to the question about condom use. Furthermore, in the self-applied questionnaire, the participants were also asked to compare their level of honesty in answering the questions in the verbal and self-administered parts of the survey. In reply, 8 out of every 10 participants said they had been equally honest in both parts of the survey, while the remaining 2 out of 10 said they had been more honest in the written questionnaire than in the one-on-one interview. For this reason, analysis of the sensitive questions (on sexual practices, including condom use) was based on the data from the self-applied questionnaires, under the assumption that this questionnaire contained more reliable answers.

\section{Qualitative Component}

The qualitative information complemented the quantitative results of the panel study. Three qualitative studies were carried out in three consecutive years $(2004,2005$, and 2006) in the same sites as the surveys. Two of the studies also included the city of Bilwi (Puerto Cabezas) in Nicaragua's Caribbean coast region. The studies looked at three different groups of young people - those linked with local organizations; participants from the panel study; and young people not linked in any way to organizations, SDSI, or the study. Adults linked to local organizations were also included.

\section{First qualitative study (qualitative 1, or qualitative baseline study)}

The qualitative baseline study was implemented in 2004 in the same cities as the panel study, as well as in the city of Bilwi. It stressed the perception of the local environment and-given that it took place after the project had started and after the first season of the TV series had ended-also evaluated the acceptance and immediate effects of SDSI. In all, 16 focus groups were held with young people: 8 groups were held with youth who were linked and 8 with those not linked to organizations allied to SDSI; 10 group interviews were held with representatives of local organizations. A total of 100 young people and 45 leaders of organizations participated. The principal issues explored included: the main 
problems related to the local social context, the communication media, (interpersonal) communication on the issues of interest, alliances among organizations, social and personal support, social attitudes and norms regarding HIV, gender-related norms (machismo), domestic violence and sexual abuse, homosexuality/lesbianism, stigma, and acceptance of Sexto Sentido TV and Radio.

\section{Second qualitative study (mid-term study, or panel study exploration)}

The second qualitative study was carried out at the end of 2005 with young people from the three cities included in the panel study, in an attempt to explore the comparative results between the first and second surveys in greater depth. The study sought to better understand some of the elements that may have contributed to changes in the study population and the interaction between those changes and the SDSI components. The study also aimed to better understand and interpret results that were unexpected or confusing. A total of 45 in-depth interviews were held, two-thirds with young people from the study panel and the rest with young people from the general population (the control group).

In addition, the study sought to identify sources of information and influence that could contribute to the changes revealed in the comparison of the first two surveys. The following were explored: perception of changes in the local social context, gender norms and opinions on gender equity, risk perception, individual and collective self-efficacy, couple communication on HIV, the use of sexual and reproductive health service providers, motivation to take an HIV test, and the consequences of the panel study.

\section{Third qualitative study (or study of the local social context and alliances)}

The third qualitative study sought to examine the possible links between the implementation of SDSI and changes in the local environment and in collective processes. The study sought to ascertain, both from young people and from adults at allied organizations, the local social context and possible links between SDSI and the changes perceived in the local social context. The intention was to use this approach to collect information on the effects of SDSI and the dynamic relationship between the different project components on both the individual and organizational levels. For reasons of time and budget, this study was carried out in only two of the three panel study cities (Estelí and Juigalpa) and in Bilwi. A total of 39 individual interviews were conducted with representatives from 21 civil society organizations, five state entities, three local coordination bodies, and nine local media outlets. Four focus groups were also conducted (one in Estelí, one in Juigalpa, and two in Bilwi), with the participation of 39 young people ( 24 women and 15 men).

A central part of this third qualitative study was to explore the mass communication processes and linkages of SDSI's different mass communication components to changes in the local social context. It also evaluated the impact of the processes of capacity building, networking, and participation in coalitions, as well as linkage of the different components vis-à-vis the target groups. It also evaluated the degree to which allied organizations and institutions incorporated the topics and approaches into their own work. 


\section{Monitoring Implementation}

Monitoring actions provided feedback to the SDSI coordinating team before, during, and after the implementation of the different components of the project. For example, addressing the subject of HIV on Sexto Sentido was consistent with the demands expressed by young people during the program's previous season and the cast tours. The monitoring processes provided follow-up information and analyzed, among other sources, the telephone calls to the radio program, the compilation of suggestions made by the audience and participants during cast tours, focus groups held with TV viewers, interviews with allied organizations, and monitoring activities in coordination with health and social service providers.

\section{Triangulation of Results: Integration of Quantitative and Qualitative Data}

The various findings were integrated by means of a "triangulation" process, in other words, comparing data derived from multiple sources and using multiple methods. Tables were created for each SDSI objective in order to compare the various findings. In addition, multiple sources of qualitative data were used to further explore or explain certain findings of the panel study. The qualitative studies have also generated specific information for certain SDSI components, such as the local context and social mobilization. Finally, the data were also integrated and reviewed by researchers affiliated with different organizations (CIDS, PATH, Horizons) and by independent researchers. 


\section{Results}

This section contains the major sociodemographic characteristics of both the study sample and the group most exposed to Somos Diferentes, Somos Iguales, as well as the main findings of the longitudinal analysis and the qualitative studies.

\section{Characteristics of the Sample}

The quantitative longitudinal analysis incorporates information corresponding to the survey "survivors" (people who participated in all three surveys). The sample's main sociodemographic characteristics are presented below. As would be expected of a longitudinal study, the sample's characteristics vary over time, with the exception of the time-independent variables of sex and location.

Based on the ages of the respondents at the time of the final survey, two age groups were formed for the analysis: 18 and under and 19 and over. This grouping corresponds to the age range for young people proposed by the United Nations. (At the beginning of the study, the participants were all between the ages of 13 and 25.) Table 2 shows the sample's distribution by age and other factors over the course of the three quantitative surveys.

Surveys in distinct years focused on collecting different background data on participants. The first survey explored poverty and ownership of a television; questions related to religion were included in the final survey. Religious affiliation or practice was assessed to determine whether exposure or other variables were conditioned by a religious profile. The poverty index for determining the participants' socioeconomic level in this study was the unmet basic needs (UBN) method, which classifies subjects or households as either "poor" or "non-poor" according to a series of variables, including electricity and potable water connections, sanitation, type of floor and walls, ownership of a radio and television, and the economic activity of household members.

The population in the SDSI study had a greater percentage of respondents categorized as "poor" than the national rate for urban households reported by the National Institute of Development Information (INIDE) in their 2005 National Household Survey to Measure Standard of Living (MECOVI). This may be due to methodological differences. MECOVI measured the incidence of poverty based on minimal consumption to satisfy basic needs, and revealed a national poverty rate of 50 percent (20 percent in extreme poverty), while for the urban population the percentage living below the poverty line was 31 percent (compared to 45 percent of this study's sample). The results regarding the presence of a television in the house were similar to the figures recorded in the National Institute for Statistics and Censuses' 2002 Demographic and Health Survey, which reported televisions in 85 percent of the urban households in these three municipalities. 
Table 2 Demographic and other relevant sociocultural characteristics of the sample

\begin{tabular}{|c|c|c|c|}
\hline Variables & $\begin{array}{c}\mathrm{I}-2003 \\
\% \\
\end{array}$ & $\begin{array}{c}\text { II-2004 } \\
\% \\
\end{array}$ & $\begin{array}{c}\text { III-2005 } \\
\% \\
\end{array}$ \\
\hline \multicolumn{4}{|l|}{ Sex } \\
\hline Female & 54 & 54 & 54 \\
\hline Male & 46 & 46 & 46 \\
\hline \multicolumn{4}{|l|}{ Age } \\
\hline 18 years or under & 62 & 53 & 44 \\
\hline 19 years or over & 38 & 47 & 56 \\
\hline \multicolumn{4}{|l|}{ Municipality (city) } \\
\hline Estelí & 28 & 28 & 28 \\
\hline León & 35 & 35 & 35 \\
\hline Juigalpa & 38 & 38 & 38 \\
\hline Has a partner** & 39 & 45 & 60 \\
\hline Has one or more children & 15 & 21 & 24 \\
\hline Poor* & 45 & $\mathrm{n} / \mathrm{a}$ & $\mathrm{n} / \mathrm{a}$ \\
\hline Is currently in school & 70 & 63 & 58 \\
\hline \multicolumn{4}{|l|}{ Last level of schooling } \\
\hline Primary & 19 & 16 & 12 \\
\hline Secondary & 64 & 63 & 61 \\
\hline Higher/university & 15 & 19 & 22 \\
\hline Currently working & 19 & 32 & 43 \\
\hline \multicolumn{4}{|c|}{ Importance of religion in his/her life* } \\
\hline Little or none & $\mathrm{n} / \mathrm{a}$ & $\mathrm{n} / \mathrm{a}$ & 19 \\
\hline Important or very important & $\mathrm{n} / \mathrm{a}$ & $\mathrm{n} / \mathrm{a}$ & 81 \\
\hline \multicolumn{4}{|l|}{ Religious affiliation* } \\
\hline Catholic & $\mathrm{n} / \mathrm{a}$ & $\mathrm{n} / \mathrm{a}$ & 57 \\
\hline Evangelical/other Protestant & $\mathrm{n} / \mathrm{a}$ & $\mathrm{n} / \mathrm{a}$ & 28 \\
\hline None & $\mathrm{n} / \mathrm{a}$ & $\mathrm{n} / \mathrm{a}$ & 15 \\
\hline \multicolumn{4}{|l|}{ Frequency of church attendance ${ }^{*}$} \\
\hline Once or twice a week & $\mathrm{n} / \mathrm{a}$ & $\mathrm{n} / \mathrm{a}$ & 39 \\
\hline Occasionally & $\mathrm{n} / \mathrm{a}$ & $\mathrm{n} / \mathrm{a}$ & 35 \\
\hline Doesn't go & $\mathrm{n} / \mathrm{a}$ & $\mathrm{n} / \mathrm{a}$ & 27 \\
\hline Affiliation with an organization & 19 & 22 & 17 \\
\hline Has a group of friends & 79 & 81 & 73 \\
\hline Has a television at home* & 93 & $\mathrm{n} / \mathrm{a}$ & $\mathrm{n} / \mathrm{a}$ \\
\hline
\end{tabular}

*Based on questions asked in only one of the surveys.

**The word "partner" referred to different kinds of relationships (boyfriend/girlfriend, live-in partner, husband/wife). 


\section{Perception of the Social Context}

An index was created to evaluate aspects of young people's perception of their social context, that is, the environment in which they live and operate. This variable was not considered a results variable; rather it was created to better understand the relationship - if any-between perceptions of the local context and individual responses on other issues.

The results of the three surveys show a tendency toward a gradual reduction in the index. This can be interpreted as a perception of deterioration in the local social context. There was a greater perception of deterioration in the social environment among women than among men $(\mathrm{p}<.001)$; and in Juigalpa in relation to Estelí and León $(\mathrm{p}<.001)$.

It is important to note that the general linear model revealed that this deterioration was not associated in any way with exposure to SDSI. On the contrary, SDSI was in fact positively associated with greater collective efficacy, that is, the perception that young people and the people around them (peers, neighbors) could do something together.

The qualitative studies help explain young people's perception of the deterioration in the local social context. Problems in the local environment commonly identified over the three years included drugs, alcoholism, youth gangs, unemployment, poverty, violence, and adolescent pregnancy.

It was also seen that to a large extent the perception of the local context or social environment was linked to both personal experiences and external events. New responsibilities and life experiences as a result of aging and maturing, as well as gender, are all elements that appear to affect this perception of social deterioration. The kind of negative experiences that might accompany the experience of being part of a couple, for example, may vary greatly for women and men.

In the first qualitative study the participants reflected on negative "changes" perceived in their local social context, such as the presence and increase in the consumption and abuse of drugs, which one survey participant commented, "are sold like candy now" (Qualitative study 1; non-organized male; Juigalpa).

The second qualitative study also found that fewer positive changes were perceived in Juigalpa, particularly in relation to the administration of the city authorities. In Estelí and León, meanwhile, many more adolescents and young people talked about the achievements and good work of certain organizations and local government institutions. In the case of Estelí, they also mentioned growing trade.

The last mayor's administration was pretty good. You could see a lot of projects, such as new paved streets, bridges, barrios surveyed.

Qualitative study 2; adolescent male from the panel study in Estelí

Let's say that the most important thing that's happened here in Esteli is the growth in trade. That generates more employment here in the city.

Qualitative study 2; adolescent male from the panel study in Estelí 


\section{Scope and Characteristics of Exposure to SDSI}

This section contains data related to exposure to and acceptance of the different components of the SDSI project: Sexto Sentido TV and Sexto Sentido Radio; billboards; and the pamphlet, "We need to be able to talk." The components related to training and coordination with other organizations were studied qualitatively.

\section{Definition of "exposure" for the purposes of the impact analysis}

Given that exposure to the SDSI project was so widespread - by the end of the intervention, nine out of every ten people interviewed knew at least the Sexto Sentido TV series - it was impossible to identify a robust "non-exposed" group for the purposes of comparison (see Figure 2).

Figure 2 Exposure to SDSl's mass communication components

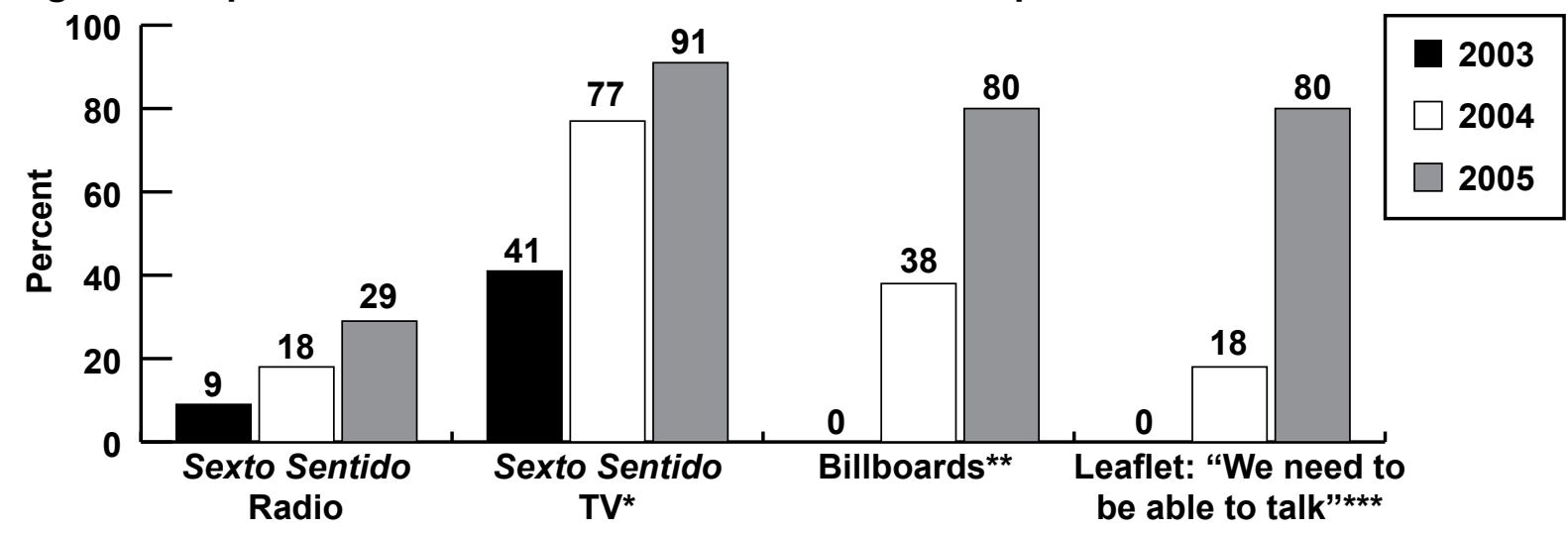

*The 2003 survey was carried out before the first of the project's three seasons went on air. Respondents were asked how much they remembered of the series two years after the first season had been broadcast.

${ }^{* *}$ The billboards had been only recently put up at the time of the 2004 survey.

***There had still been no mass distribution of the pamphlets at the time of the 2004 survey.

Analysis revealed that people who had listened to Sexto Sentido Radio and/or had seen the leaflet or highway billboard had also seen Sexto Sentido TV. It was therefore decided to use exposure to Sexto Sentido TV as the measure of approximation for analyzing the impact of exposure to SDSI.

For the purposes of comparison, the sample was divided into two groups: one with "greater exposure" and another with "less exposure" (see Box 1).

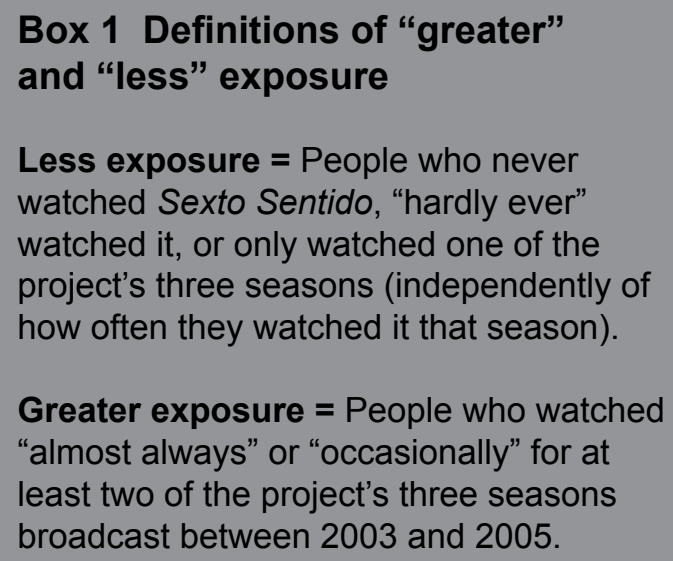

Box 1 Definitions of "greater" and "less" exposure

Less exposure $=$ People who never watched Sexto Sentido, "hardly ever" watched it, or only watched one of the project's three seasons (independently of how often they watched it that season).

Greater exposure = People who watched "almost always" or "occasionally" for at least two of the project's three seasons broadcast between 2003 and 2005. 


\section{Exposure to Sexto Sentido TV}

Sexto Sentido TV was widely seen on a regular basis by a large part of the adolescent and youth population (see Figure 3).

\section{Figure 3 Exposure to Sexto Sentido TV}

Did not watch the series, "hardly ever" watched it, or only watched one season (less exposure)

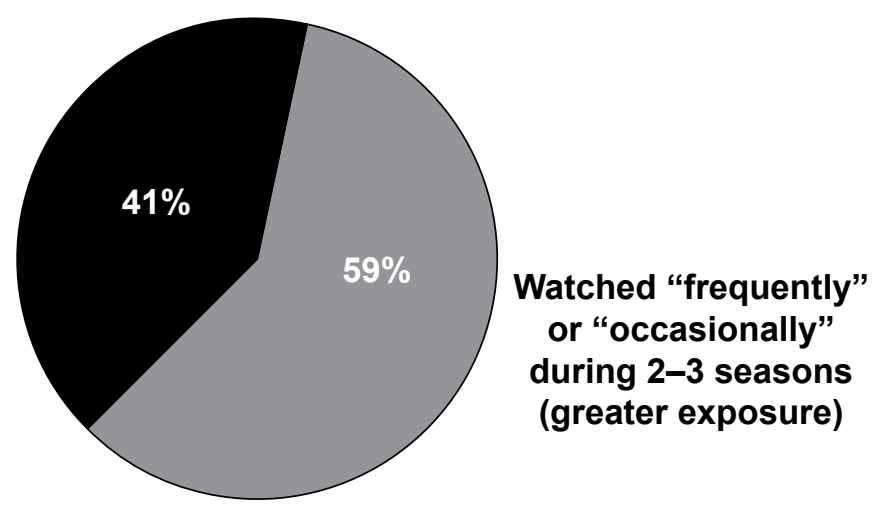

\section{Differences by municipality}

The geographical location of viewers (the municipality in which they live) was a relevant factor in terms of exposure to the different SDSI components (see Figure 4). In the case of both Sexto Sentido Radio and Sexto Sentido TV, the municipality with the largest "loyal" audience was Juigalpa, the most socially conservative municipality with the fewest organizations working on the issues dealt with by SDSI.

Figure 4 Exposure by municipality (2005)

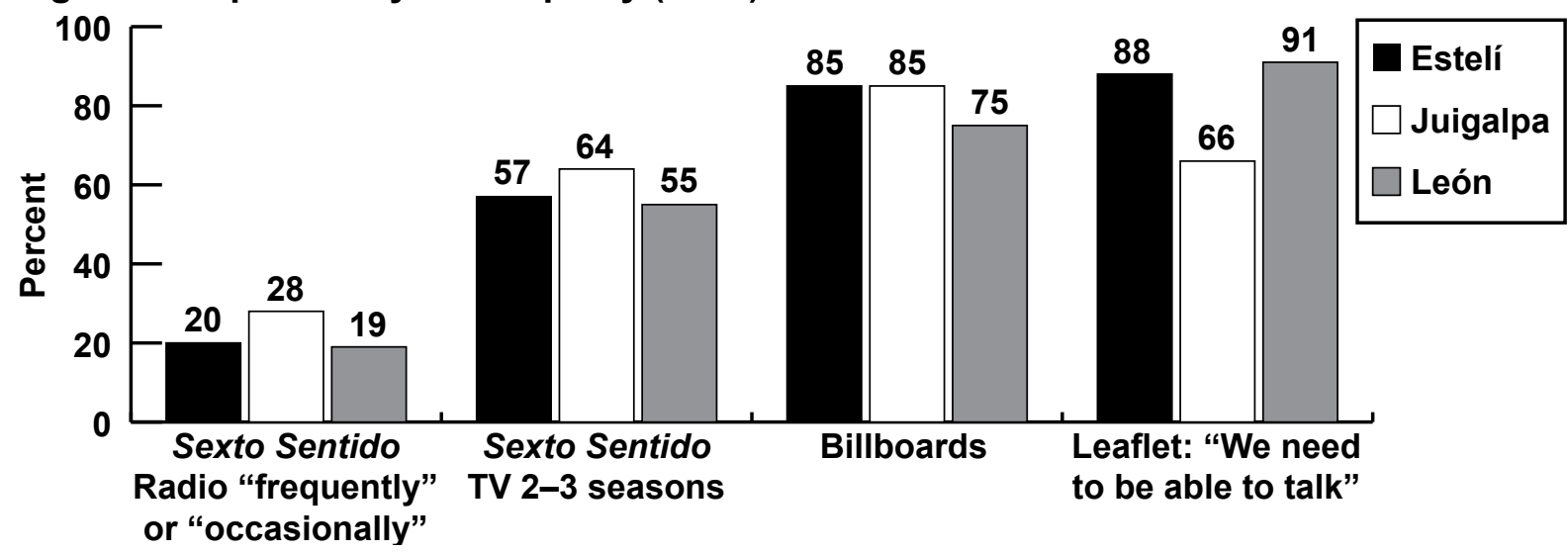


Projected number of "more exposed" young people

Given that the samples are representative of the places where the survey was carried out, it is possible to project the "more exposed" youth populations in these three localities (see Table 3). This was done by applying the percentage of youth with "greater exposure" found in each municipality to each department's overall urban population between the ages of 15 and 24 (INIDE 2005).

Table 3 Projected youth with greater exposure by municipality

\begin{tabular}{lccc}
\hline Department & $\begin{array}{c}\text { Urban adolescent and } \\
\text { youth population } \\
\text { (15-24 years) }\end{array}$ & $\begin{array}{c}\text { \% of greater } \\
\text { exposure per } \\
\text { municipality }\end{array}$ & $\begin{array}{c}\text { \# of adolescents and } \\
\text { young people (15-24 } \\
\text { years) with greater } \\
\text { exposure }\end{array}$ \\
\hline Estelí & 27,249 & 55 & 14,905 \\
Chontales (Juigalpa) & 19,935 & 64 & 12,738 \\
León & 47,448 & 57 & 27,188 \\
Sub-total for the 3 areas & 94,632 & & 54,831 \\
\hline
\end{tabular}

The real audience in these departments may be substantially larger than the combined 54,831 calculated in the sample, since the sample only included young people over the age of 13 years. The same calculation based on the 10-29 year-old population gives a projection of 105,346 people with "greater exposure" residing in the three departments. In addition, half of those who watched Sexto Sentido TV said they did so with other people, with a large proportion saying they did so with "the whole family."

\section{National projection ${ }^{6}$}

Although the study sample is not representative nationally, it is possible to make a conservative national projection, applying the average percentage for the three municipalities (59 percent) to the national urban population of 15-24 year olds and 10-29 year olds (see Table 4).

Table 4 Projected national exposure by youth

\begin{tabular}{lccc}
\hline Whole country & $\begin{array}{c}\text { Urban adolescent/ } \\
\text { youth population }\end{array}$ & $\begin{array}{c}\text { \% greater exposure } \\
\text { (average) }\end{array}$ & $\begin{array}{c}\text { \# adolescents/young } \\
\text { people with greater } \\
\text { exposure }\end{array}$ \\
\hline Age 15-24 years & 644,711 & 59 & 380,379 \\
Age 10-29 years & $1,236,922$ & 59 & 729,784 \\
\hline
\end{tabular}

\footnotetext{
${ }^{6}$ Sexto Sentido TV is also broadcast in other countries, but those audiences were not studied.
} 
In addition to the municipality, other relevant factors were:

- Sex: Proportionally more women than men watched Sexto Sentido TV, with 64 percent of the women interviewed falling in the "greater exposure" group, as compared with 53 percent of men.

- Education: A larger proportion of people who had reached secondary school or entered a university watched the program than people who had only had primary school education.

- Work: A greater proportion of people without paid work watched the program compared to those with paid work.

The analysis showed that other important sociodemographic factors are in fact uncorrelated with level of exposure to Sexto Sentido. The factors analyzed included:

- Age: An equal proportion of adolescents (13-17 years) and youth (18-24 years) watched the series.

- Economic level: An equal proportion of "poor" and "non-poor" people watched the series.

- Religion: There was no correlation between religion and exposure rates. No differences were discovered between varying levels of exposure to Sexto Sentido and religious characteristics, including: the importance of religion in an individual's life, belonging to a particular religion, or the frequency with which an individual attended church (see Box 2).

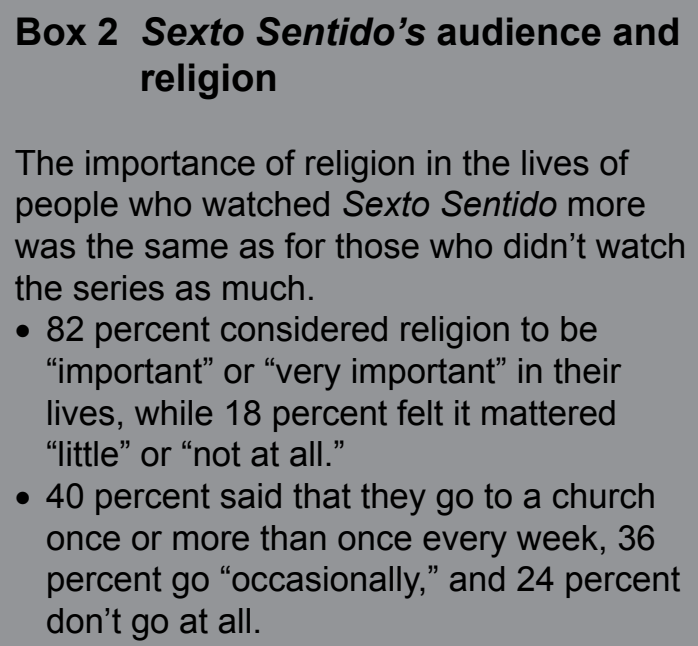

- 40 percent said that they go to a church once or more than once every week, 36 percent go "occasionally," and 24 percent don't go at all.

- Affiliation with an organization: An equal proportion of people affiliated with and not affiliated with an organization watched the series.

- Having or not having children: An equal proportion of people with and without children watched the series.

\section{Exposure to other components}

\section{Sexto Sentido Radio}

The proportion of people who had listened to the Sexto Sentido Radio program increased substantially over time, from 9 percent in 2003 to 29 percent in 2005. It was found in 2005 that half of the people who had heard the radio program at some time said they had done so within the previous six months.

The vast majority of those who had listened reported having listened to the daily program "occasionally" or "frequently." Between 2003 and 2005, this proportion increased from 74 percent to 82 percent, with a greater increase among women, thus evening out the proportion of women and men in the program's regular audience. In 2005, 23 percent of all the participants surveyed said that they listened to Sexto Sentido Radio more or less regularly. In light of the level of competition for radio 
audiences due to the enormous number of stations, Sexto Sentido Radio's captive audience is relatively high. Audience calculations were limited to the populations in these three municipalities (INIDE 2005) because the frequencies of the radio stations didn't reach farther than the municipality.

Table 5 Exposure to Sexto Sentido Radio by municipality (2005)

\begin{tabular}{lccc}
\hline City & $\begin{array}{c}\text { Urban adolescent/ } \\
\text { youth population } \\
\text { (15-24 years) }\end{array}$ & $\begin{array}{c}\text { \% listening } \\
\text { "occasionally" or } \\
\text { "frequently" }\end{array}$ & $\begin{array}{c}\text { \# of adolescents/ } \\
\text { youths (15-24 years) } \\
\text { with greater exposure }\end{array}$ \\
\hline Estelí & 20,985 & 24 & 4,973 \\
Juigalpa & 9,825 & 28 & 2,790 \\
León & 31,638 & 19 & 6,043 \\
Sub-total for the 3 cities & 62,448 & & 13,806 \\
\hline
\end{tabular}

Using the same method of calculation, the audience calculation for 2005 doubles to 27,352 when the other five small cities where Sexto Sentido Radio was broadcast are taken into account. ${ }^{7}$ This estimate excludes the Managua audience, which is too difficult to calculate given the competition among radio stations and the lack of trustworthy ratings studies.

The "We need to be able to talk" pamphlets

The "We need to be able to talk" pamphlets were distributed toward the end of 2004 through organizations linked with Puntos de Encuentro. They were also distributed during the Sexto Sentido cast tours to various Nicaraguan cities.

By the last survey, eight out of every ten people interviewed said they had seen the leaflet. More women than men had seen it ( 86 percent versus 75 percent), and there were also important differences according to the municipality (Estelí: 88 percent; Juigalpa: 66 percent; León: 91 percent). This is possibly due to the fact that there were relatively fewer organizations in Juigalpa to distribute the pamphlets compared to the other municipalities.

\section{Billboard signs}

Billboard signs were posted in all 15 departmental capitals as well as the capitals of the two Atlantic Coast Autonomous Regions. The billboards displayed information about the local health and social services people could access. They were initially posted during the second half of 2004 in preparation for the second season of Sexto Sentido TV. Their contents were then changed at the beginning of 2005, prior to the final season.

During the last survey, eight out of every ten people interviewed said they had seen the billboard in their city. Unlike the pamphlets, the municipalities where the billboard was best known were Estelí

\footnotetext{
${ }^{7}$ Multiplying the population of the cities by 23 percent, which is the average proportion that listens to the program "frequently" or

"occasionally." The other cities are: Boaco, Chinandega, Masaya, Jinotega, and Somoto.
} 
and Juigalpa, both with 85 percent, while only 71 percent knew about the billboard in León. This could be because the billboard in León was located on the outskirts of the city, while in Estelí and Juigalpa they were more centrally located.

\section{Other activities}

As might be expected, the project's non-mass communication activities occurred on a smaller scale than the mass-communication activities. For example, only 6 percent of survey participants said they had attended an activity held by the Sexto Sentido TV cast in their area.

\section{Dynamics of the Sexto Sentido TV and radio audiences (national versus local)}

\section{Sexto Sentido TV}

Channel 2, the most watched channel in the country, with almost national coverage, was mentioned by nine out of ten people as the channel on which they watched Sexto Sentido. ${ }^{8}$ Some people in each locality mentioned that they watched the series on their local cable service: 14 percent of those interviewed in Juigalpa mentioned Channel 14; 8 percent of people in Estelí mentioned Telenorte de Esteli; and 5 percent in León mentioned Channel 55.

\section{Sexto Sentido Radio}

Unlike Sexto Sentido TV - and unlike previous years when Sexto Sentido Radio was only broadcast by one station located in Managua - the surveys for this study demonstrated the importance of local stations in the radio network that simultaneously broadcast Sexto Sentido Radio. In each of the three cities included in the panel study, the study participants mentioned their local radio station as the main station through which they listened to the program. ${ }^{9}$ The study also revealed an increase in the program audience in each of the cities, with notable increases in Estelí and León over time, although the program continued to be most listened to in Juigalpa.

Impact of the change of time slot on the audience of Sexto Sentido $T V$

Generally speaking, people who watched Sexto Sentido TV saw it with certain regularity. In 2004, 72 percent of all people surveyed watched Sexto Sentido TV "frequently" or "occasionally." In 2005, however, this percentage dropped to 54 percent.

\section{The time slot does matter}

After the program's time slot was changed in 2005, 80 percent of those who didn't watch Sexto Sentido said it was "because of the time slot" or "because of a lack of time."

${ }^{8}$ This study was done before the series' re-broadcast by the national cable channel, Channel 11.

${ }^{9}$ These radio stations are: Stereo Mundo in Estelí, Radio Centro in Juigalpa, and La Amistad in León. 
The reasons for this drop appear to be strongly linked to the change in the show's timeslot. For the series' last season, in 2005, Channel 2 changed the timeslot from early Sunday evening to noon on the same day. Over 80 percent of people who said they didn't watch the program in 2005 said it was "because of the time slot" or "because of a lack of time" (see Figure 5).

The qualitative study identified that the new time slot clashed with activities such as church going, housework, or preparing lunch. Only 7 percent of those who didn't watch the program said it was because they weren't interested or didn't like it, while 4 percent said they did not have a television.

Figure 5 Reasons for not watching Sexto Sentido TV (2005)

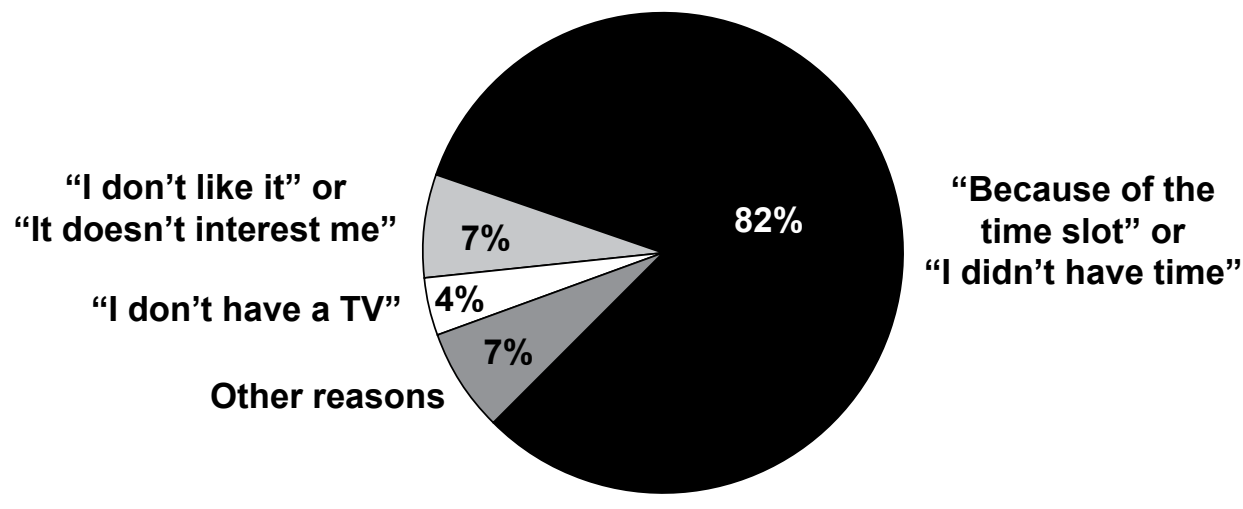

\section{Acceptance}

\section{Sexto Sentido TV}

While the total "frequent" viewer audience fell in 2005, acceptance of the series increased among those who did watch it. In 2004, half of the respondents who watched the show said that they liked it "quite a lot," a figure that rose to two-thirds of respondents in 2005 (see Figure 6).

Figure 6 Like Sexto Sentido TV "quite a lot"

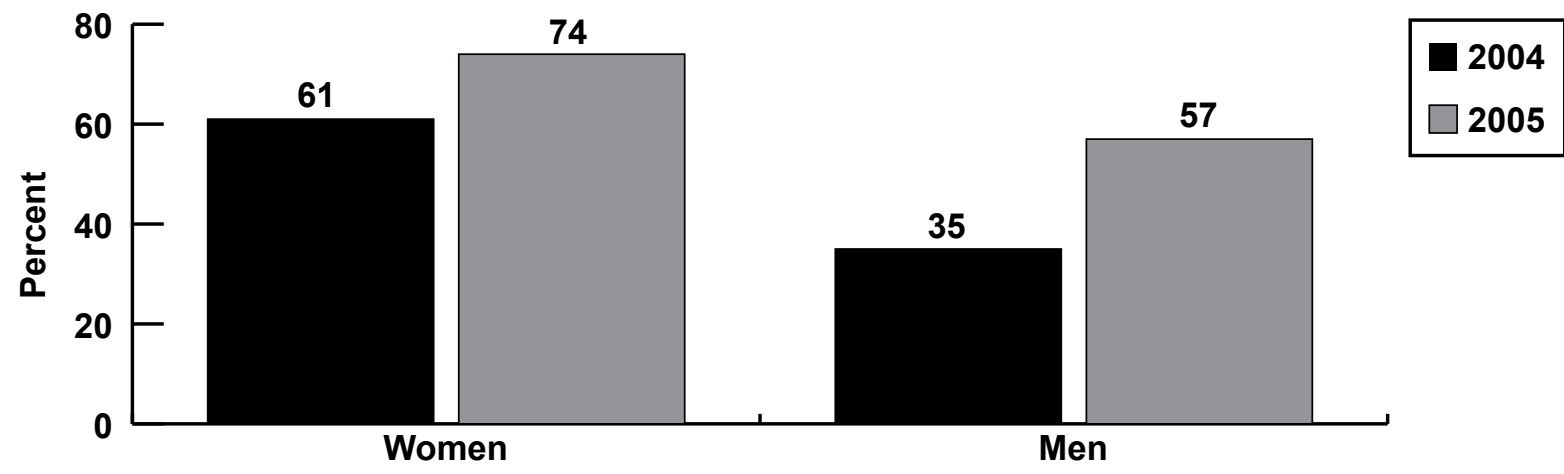


Between 2004 and 2005, there was also an increase in the proportion of people who spontaneously mentioned Sexto Sentido TV as a response to an open question about their favorite nationally produced TV programs on Sundays. In 2004, four out of every ten people mentioned Sexto Sentido spontaneously. This figure rose to six in ten respondents in 2005, with more women mentioning it than men. At the same time, the popularity of the show increased among men over time, from 29 percent citing it as their favorite nationally produced show in 2004 to 57 percent in 2005 (see Figure 7). In fact, for the first time in Sexto Sentido's history, an equal proportion of men and women watched the series in 2005.

Figure 7 Respondents who mentioned Sexto Sentido spontaneously

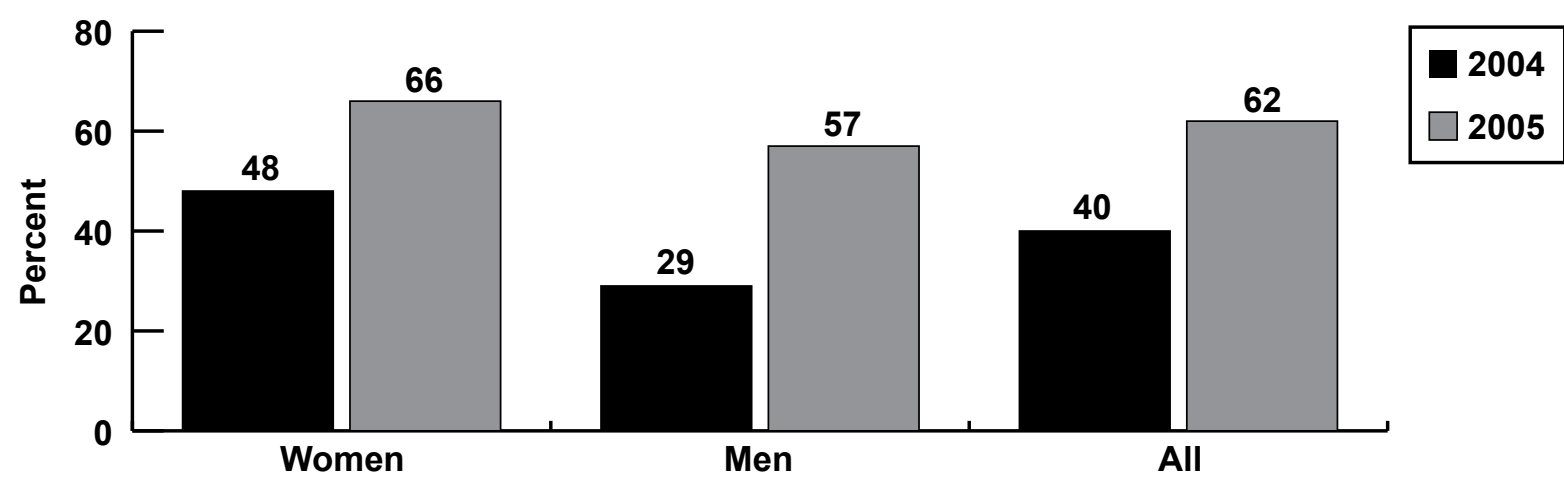

The increase in acceptance of the show suggests that if the timeslot had not been changed in 2005, the audience for the last season would have grown, which would have raised the percentage of people in the "more exposed" category.

\section{Importance of the subject of HIV in the SDSI project}

Prior to surveying participants about Sexto Sentido, the questionnaires surveyed whether respondents knew someone who either has or has died of HIV. Respondents were also asked if they had seen someone with HIV on TV. As Figure 8 shows, a far greater percentage of the surveyed population had seen someone with HIV or AIDS on TV than had personally known a person with HIV or AIDS. The percentage of people who had seen someone with HIV or AIDS on television grew between 2004 and 2005, with a significantly higher increase among men (from 62 percent to 74 percent). Of the total number of people who had seen someone with HIV on television, 61 percent spontaneously mentioned Sexto Sentido as the show on which they had seen that person. 
Figure 8 Knows someone or has seen a television character with HIV or AIDS

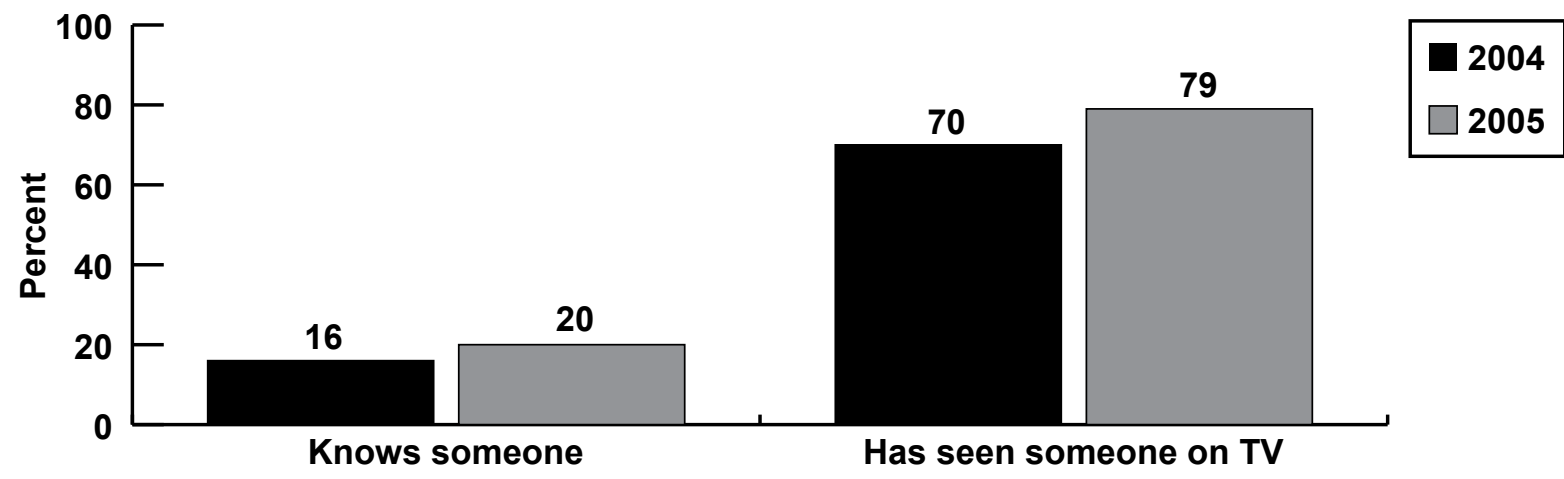

HIV was also the issue most mentioned by both Sexto Sentido TV viewers and Sexto Sentido Radio listeners when asked what issue had made them think most. Half of the TV viewers and radio listeners mentioned HIV (more women than men), followed by a third who mentioned domestic violence/sexual abuse (again, more women than men). Drugs were the third most commonly mentioned issue (in this case mentioned by more men than women).

\section{Impact of SDSI}

Two types of results were generated: those that identify or describe the accumulated effect of exposure to SDSI over time through the use of continuous variables (e.g., indices); and those that identify the probability of an effect being due to exposure to SDSI through the use of categorical dichotomous variables (e.g., having used or not having used a condom the last time they had sexual relations). In both cases multivariate analysis was used in order to adjust the effect of the independent variable of interest (exposure to SDSI) on a range of dependent variables. The multivariate analysis isolated the effect of SDSI exposure by controlling for a range of other factors that could potentially affect the dependent variables, namely, municipality, sex, education, and age.

\section{Summary of results}

Table 6 summarizes the main attributable effects of greater exposure to SDSI. The results are described and discussed in greater depth following the table. 
Table 6 Summary results

\begin{tabular}{|c|c|c|}
\hline Impact & Results $^{10}$ & Population attributable risks (PAR) ${ }^{11}$ \\
\hline $\begin{array}{l}\text { Greater gender } \\
\text { equity }\end{array}$ & $\begin{array}{l}\text { Participants with greater exposure } \\
\text { to SDSI had higher scores (i.e. more } \\
\text { gender-equitable attitudes) throughout the } \\
\text { intervention period than participants with } \\
\text { less exposure to SDSI. }\end{array}$ & $\begin{array}{l}\text { The following are attributable to greater } \\
\text { exposure to SDSI: } \\
\text { - The attitude of } 22 \text { percent of those } \\
\text { respondents who do not agree with } \\
\text { the statement that "women who carry } \\
\text { condoms in their bags are easy" (15,377 } \\
\text { young people in the } 3 \text { cities). } \\
\text { - The attitude of } 17 \text { percent of those } \\
\text { respondents who do not believe that } \\
\text { women are the ones who are responsible } \\
\text { for avoiding pregnancy (12,128 young } \\
\text { people in the } 3 \text { cities). } \\
\text { The attitude of } 11 \text { percent of those } \\
\text { respondents who do not believe } \\
\text { women should be solely responsible for } \\
\text { housekeeping and caring for the children } \\
\text { ( } 7,326 \text { young people in the } 3 \text { cities). }\end{array}$ \\
\hline $\begin{array}{l}\text { Reduced } \\
\text { stigma }\end{array}$ & $\begin{array}{l}\text { Participants with greater exposure to SDSI } \\
\text { had higher scores (i.e. less stigmatizing } \\
\text { attitudes) throughout the intervention period } \\
\text { than participants with less exposure to } \\
\text { SDSI. } \\
\text { In addition, participants with great exposure } \\
\text { to SDSI showed: } \\
\text { - Greater increase over time in percentage } \\
\text { of respondents who would maintain a } \\
\text { friendship with a homosexual friend. The } \\
\text { percentage rose from } 36 \text { percent in } 2003 \\
\text { to } 49 \text { percent in } 2005 \text { among those more } \\
\text { exposed to SDSI; it rose from } 23 \text { percent } \\
\text { to } 32 \text { percent during the same time } \\
\text { period among those with less exposure } \\
\text { (p<0.05). } \\
\text { Greater increase over time in the } \\
\text { percentage of respondents who would } \\
\text { maintain a friendship with a lesbian } \\
\text { friend. The percentage rose from } 38 \\
\text { percent in } 2003 \text { to } 48 \text { percent in } 2005 \\
\text { among those more exposed to SDSI; } \\
\text { it rose from } 26 \text { percent to } 31 \text { percent } \\
\text { among those with less exposure ( }<< \\
\text { 0.05). }\end{array}$ & $\begin{array}{l}\text { The following are attributable to greater } \\
\text { exposure to SDSI: } \\
\text { - } \quad \text { The attitude of } 19 \text { percent of those } \\
\text { respondents who would eat at the same } \\
\text { table as a person with HIV (15,673 young } \\
\text { people in the } 3 \text { cities). } \\
\text { - The attitude of } 17 \text { percent of those } \\
\text { respondents who believe prostitutes are } \\
\text { not to blame for HIV (9,856 young people } \\
\text { in the } 3 \text { cities). } \\
\text { - The attitude of } 18 \text { percent of those } \\
\text { respondents who believe that people } \\
\text { with HIV shouldn't feel ashamed (15,597 } \\
\text { young people in the } 3 \text { cities). } \\
\text { - The attitude of } 18 \text { percent of those } \\
\text { respondents who would be willing to be } \\
\text { friends with someone with HIV (13,901 } \\
\text { young people in the } 3 \text { cities). } \\
\text { - The attitude of } 20 \text { percent of those } \\
\text { respondents who said they would } \\
\text { continue being friends with someone who } \\
\text { told them he was a homosexual (16,249 } \\
\text { young people in the } 3 \text { cities). }\end{array}$ \\
\hline
\end{tabular}

\footnotetext{
${ }^{10}$ Unless otherwise noted, all results referring to increased or decreased probability are based on multivariate logistic regression (with time), and Odds Ratios, adjusted for age, sex, municipality, education, and time. Unless otherwise noted, all results mentioned are statistically significant (95\% confidence interval does not include 1.0).

${ }^{11}$ The population attributable proportions for SDSI's preventative influence were calculated for a subset of result variables. PAR $=[(\%$ of people exposed to SDSI among the positive cases) x (Odd Ratio-1)]/Odds Ratio.
} 


\begin{tabular}{|c|c|c|}
\hline $\begin{array}{l}\text { Greater } \\
\text { knowledge } \\
\text { and use of } \\
\text { health and } \\
\text { social service } \\
\text { providers }\end{array}$ & $\begin{array}{l}\text { Participants with greater exposure to SDSI } \\
\text { demonstrated: }{ }^{12} \\
\text { - } 33 \text { percent greater probability of knowing } \\
\text { a center that provides attention for cases } \\
\text { of domestic violence. }{ }^{13} \\
\text { - } 31 \text { percent greater probability of knowing } \\
\text { a center that provides attention for STIs/ } \\
\text { HIV. }{ }^{14} \\
23 \text { percent greater probability of knowing } \\
\text { a center for addressing concerns about } \\
\text { sexuality. }{ }^{15} \\
17 \text { percent greater probability of knowing } \\
\text { where to take an HIV test. }{ }^{16} \\
\text { - } 48 \text { percent greater probability of having } \\
\text { been to a center that attends to cases } \\
\text { of domestic violence in the last six } \\
\text { months. }{ }^{17} \\
\text { - } 58 \text { percent greater probability of having } \\
\text { visited an organization with concerns } \\
\text { about sexuality not related to HIV in the } \\
\text { last six months. }{ }^{18}\end{array}$ & $\begin{array}{l}\text { The following are attributable to SDSI } \\
\text { exposure: } \\
\text { - } 23 \text { percent of those respondents who } \\
\text { know a center that provides attention for } \\
\text { cases of violence (13,554 young people } \\
\text { in the } 3 \text { cities). } \\
\text { - } 20 \text { percent of those respondents who } \\
\text { know a center that provides attention for } \\
\text { STIs/HIV (14,635 young people in the } 3 \\
\text { cities). } \\
17 \text { percent of those respondents who } \\
\text { know about a center for addressing } \\
\text { issues related to sexuality ( } 9,215 \text { young } \\
\text { people in the } 3 \text { cities). } \\
29 \text { percent of those respondents who } \\
\text { in the last six months have been to a } \\
\text { center that attends to cases of domestic } \\
\text { violence ( } 2,826 \text { young people in the } 3 \\
\text { cities). } \\
25 \text { percent of those respondents who in } \\
\text { the last six months have been to a center } \\
\text { to address issues related to sexuality } \\
\text { (2,536 young people in the } 3 \text { cities). }\end{array}$ \\
\hline $\begin{array}{l}\text { Greater } \\
\text { knowledge } \\
\text { of HIV and } \\
\text { prevention }\end{array}$ & $\begin{array}{l}\text { Participants with greater exposure to SDSI } \\
\text { demonstrated: } \\
\text { - } 21 \text { percent greater probability of knowing } \\
\text { it is possible to live with HIV for many } \\
\text { years. }{ }^{19} \\
\text { - } 30 \text { percent greater probability of saying } \\
\text { that condom use can prevent HIV. }{ }^{20}\end{array}$ & \\
\hline
\end{tabular}

${ }^{12}$ These numbers are derived from adjusted Odds Ratios (adjusted for sex, age, municipality and education), with their corresponding 95\% Confidence Intervals.

${ }^{13} \mathrm{OR}=1.33 ; 95 \% \mathrm{CI}=1.2-1.5$

${ }^{14} \mathrm{OR}=1.31 ; 95 \% \mathrm{CI}=1.2-1.5$

${ }^{15} \mathrm{OR}=1.23 ; \mathrm{CI} 1.11-1.4$

${ }^{16} \mathrm{OR}=1.17 ; 95 \% \mathrm{CI}=1.0-1.3$

${ }^{17} \mathrm{OR}=1.48 ; 95 \% \mathrm{CI}=1.2-1.9$

${ }^{18} \mathrm{OR}=1.58$; CI $1.2-2.1$

${ }^{19} \mathrm{OR}=1.2 ; 95 \% \mathrm{CI}=1.1-1.3$

${ }^{20} \mathrm{OR}=1.29 ; 95 \% \mathrm{CI}=1.2-1.5$ 


\begin{tabular}{|c|c|c|}
\hline $\begin{array}{l}\text { Greater } \\
\text { personalization } \\
\text { of the risk } \\
\text { perception of } \\
\text { HIV }\end{array}$ & $\begin{array}{l}\text { Participants with greater exposure to SDSI } \\
\text { demonstrated: } \\
\text { - } 29 \text { percent greater probability of having } \\
\text { thought about their own possibility of } \\
\text { contracting HIV. } \\
\text { - Among female respondents, a } 35 \\
\text { percent greater probability of thinking } \\
\text { about their own possibility of contracting } \\
\text { HIV. }{ }^{21} \\
\text { - Among younger respondents (aged } 18 \\
\text { years and under), a } 27 \text { percent greater } \\
\text { probability of thinking about contracting } \\
\text { HIV. }{ }^{22}\end{array}$ & \\
\hline $\begin{array}{l}\text { Greater } \\
\text { interpersonal } \\
\text { communication } \\
\text { about SDSI } \\
\text { issues }\end{array}$ & $\begin{array}{l}\text { Participants with greater exposure to SDSI } \\
\text { demonstrated: } \\
\text { - } 62 \text { percent greater probability of having } \\
\text { talked with someone in the last six } \\
\text { months about domestic violence, HIV, } \\
\text { homosexuality, or the rights of young } \\
\text { people. }{ }^{23} \\
\text { (Breakdown of specific topics is as follows: } \\
\text { domestic violence: } 53 \text { percent; HIV: } 49 \\
\text { percent; homosexuality/lesbianism: } 31 \\
\text { percent; young people's rights: } 48 \text { percent.) }\end{array}$ & $\begin{array}{l}\text { The following is attributable to SDSI } \\
\text { exposure: } \\
\text { - } 21 \text { percent of those respondents who had } \\
\text { talked to someone about one of these } \\
\text { topics in the last six months (10,650 } \\
\text { young people in the } 3 \text { cities). }\end{array}$ \\
\hline $\begin{array}{l}\text { Greater } \\
\text { communication } \\
\text { with partner } \\
\text { about HIV } \\
\text { prevention }\end{array}$ & $\begin{array}{l}\text { Participants with greater exposure to SDSI } \\
\text { demonstrated: } \\
\text { - } 32 \text { percent greater probability (in } \\
\text { longitudinal analysis) of having talked } \\
\text { with their partner about condom use. }{ }^{24} \\
\text { - } 43 \text { percent greater probability of having } \\
\text { talked with their partner about taking an } \\
\text { HIV test. }{ }^{25}\end{array}$ & $\begin{array}{l}\text { The following are attributable to SDSI } \\
\text { exposure: } \\
\text { - } 23 \text { percent of those respondents who } \\
\text { said they had talked to their partners } \\
\text { about using a condom in the last six } \\
\text { months ( } 7,897 \text { young people in the } 3 \\
\text { cities). } \\
\text { - } 23 \text { percent of those respondents who } \\
\text { have talked to their partners about taking } \\
\text { an HIV test ( } 3,104 \text { young people in the } 3 \\
\text { cities). } \\
\text { - } 18 \text { percent of those respondents who } \\
\text { have talked to their partner about } \\
\text { previous sexual experiences }(4,423 \\
\text { young people in the } 3 \text { cities). }\end{array}$ \\
\hline $\begin{array}{l}\text { Greater } \\
\text { perception of } \\
\text { self-efficacy } \\
\text { to negotiate } \\
\text { condom use }\end{array}$ & $\begin{array}{l}\text { Participants with greater exposure to SDSI } \\
\text { demonstrated: } \\
\text { - Higher perception of self-efficacy } \\
\text { to negotiate condom use than non- } \\
\text { exposed respondents, despite an overall } \\
\text { reduction in self-efficacy }(p=0.033) \text {. }\end{array}$ & \\
\hline
\end{tabular}

${ }^{21} \mathrm{OR}=1.35 ; \mathrm{CI} 1.1-1.6$

${ }^{22} \mathrm{OR}=1.26$; CI $1.1-1.5$

${ }^{23} \mathrm{OR}=1.6$; CI $1.5-1.8$

${ }^{24} \mathrm{OR}=1.32 ; \mathrm{CI} 1.2-1.5$

${ }^{25} \mathrm{OR}=1.43$; CI $1.2-1.7$ 


\begin{tabular}{|c|c|c|}
\hline $\begin{array}{l}\text { Increased } \\
\text { sense of } \\
\text { equality in } \\
\text { relationships }\end{array}$ & $\begin{array}{l}\text { Participants with greater exposure to SDSI } \\
\text { demonstrated: } \\
\text { - Higher values than respondents with less } \\
\text { exposure in the power and control index } \\
\text { (i.e., the person's sense of equal power } \\
\text { in their couple relationships), despite an } \\
\text { overall reduction in the population ( } p= \\
\text { 0.025). }\end{array}$ & \\
\hline $\begin{array}{l}\text { Greater } \\
\text { interpersonal } \\
\text { and intimate } \\
\text { partner } \\
\text { communication } \\
\text { on SDSI } \\
\text { topics and HIV } \\
\text { prevention }\end{array}$ & $\begin{array}{l}\text { Participants with greater exposure to SDSI } \\
\text { demonstrated: } \\
\text { - Increased interpersonal and intimate } \\
\text { partner communication that resulted } \\
\text { in greater probability of consistent } \\
\text { condom use with both steady and casual } \\
\text { partners. (See below.) }\end{array}$ & \\
\hline $\begin{array}{l}\text { Greater } \\
\text { condom use in } \\
\text { sexual relations } \\
\text { with casual } \\
\text { partners }\end{array}$ & $\begin{array}{l}\text { Participants with greater exposure to SDSI } \\
\text { demonstrated: } \\
\text { - Greater condom use with casual partners } \\
\text { (among those who said they'd had } \\
\text { casual partners). } \\
\text { - } 44 \text { percent greater probability of having } \\
\text { used a condom during the last sexual } \\
\text { relation with a casual partner. } \\
\text { - } 42 \text { percent greater probability of having } \\
\text { consistently used a condom with casual } \\
\text { partners in the last } 6 \text { months. } \\
\text { - }{ }^{27} \\
\text { me percent greater probability among } \\
\text { during the last } 6 \text { months. }{ }^{28} \\
\text { - } 41 \text { percent greater probability (in last } \\
\text { survey) of interpersonal communication } \\
\text { about SDSI-related issues (57 percent } \\
\text { in men and } 27 \text { percent in women). } \\
\text { Interpersonal communication with a } \\
\text { casual partner resulted in a } 63 \text { percent } \\
\text { greater probability of consistent condom } \\
\text { use. (Having talked with their partner } \\
\text { about condom use resulted in a } 3 \\
\text { times greater likelihood among women } \\
\text { of consistent condom use in the last } \\
6 \text { months. }{ }^{29} \text { The increase was not } \\
\text { significant in men.) }\end{array}$ & $\begin{array}{l}\text { The following is attributable to SDSI } \\
\text { exposure: } \\
\text { - } 18 \text { percent of those respondents who } \\
\text { reported having used a condom during } \\
\text { their last sexual relations with a casual } \\
\text { partner (approximately } 2,500 \text { young } \\
\text { people in the } 3 \text { cities). }\end{array}$ \\
\hline
\end{tabular}

\footnotetext{
${ }^{26} \mathrm{OR}=1.44 ; \mathrm{CI} 1.2-1.8$

${ }^{27} \mathrm{OR}=1.42 ; \mathrm{CI} 1.1-1.9$

${ }^{28} \mathrm{OR}=1.56$; CI $1.2-2.0$

${ }^{29} \mathrm{OR}=3.06$; CI $1.3-6.9$
} 


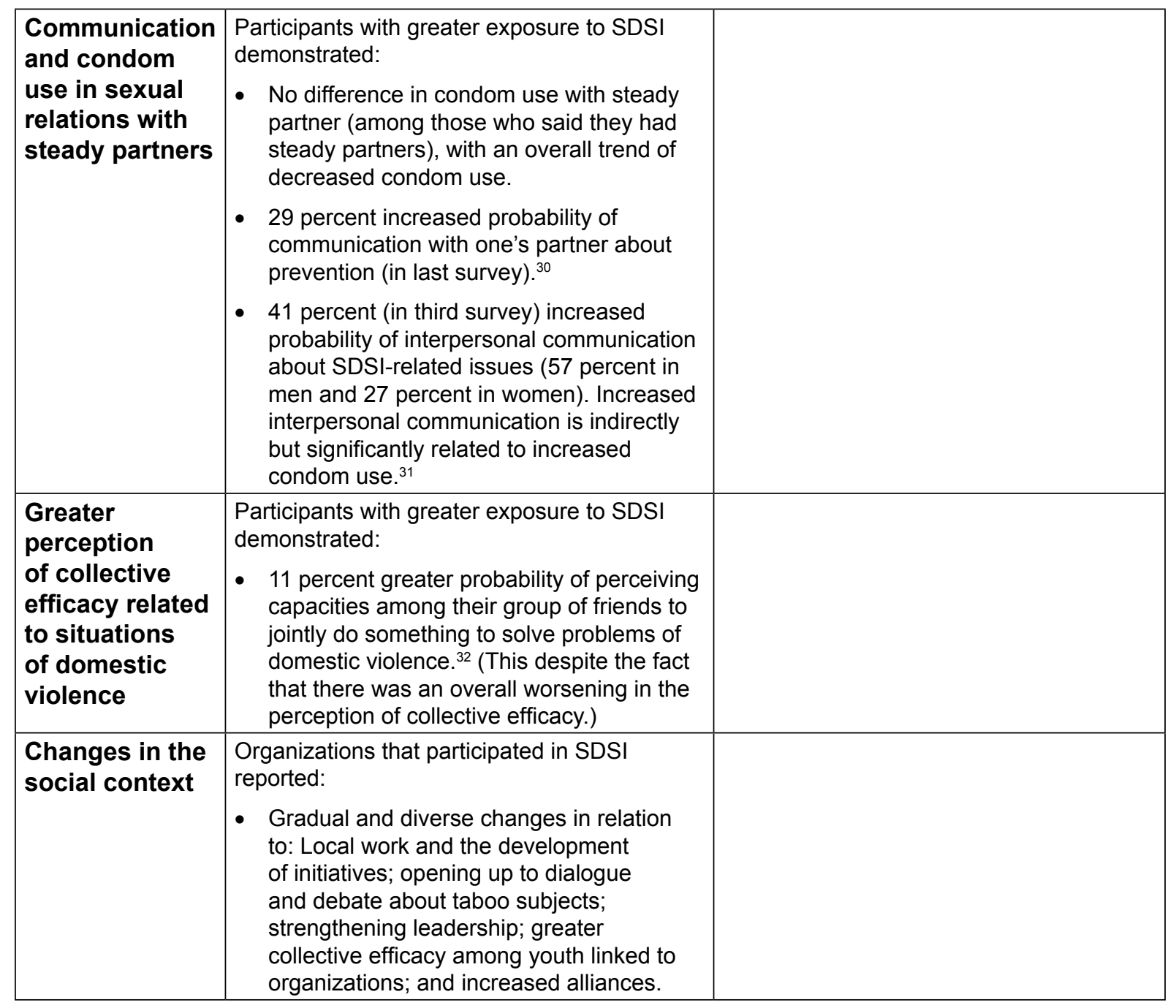

\footnotetext{
${ }^{30} \mathrm{OR}=1.31 ; \mathrm{CI} 1.2-1.5$

${ }^{31}$ Interpersonal communication is positively associated with greater personalization of risk perception (51 percent overall; 67 percent in men and 39 percent in women), and more than double probability of sense of self-efficacy ( $\mathrm{OR}=2.15$; CI $1.7-2.7)$. Greater personalization of risk perception was associated with a 62 percent greater probability of actually talking with one's partner about prevention (68 percent in men and 57 percent in women); Those with perceived self-efficacy to negotiate condom use with their partner were more than 3.5 times more likely $(\mathrm{OR}=3.57$; CI $2.7-4.8)$ to actually talk to their partner about prevention. Women were 5 times more likely to talk to their partner $(\mathrm{OR}=5.05$; CI $2.8-9.1)$, while men were 3 times more likely $(\mathrm{OR}=3.13$; CI $2.2-4.4)$. Talking about condom use with a steady sexual partner resulted in an 82 percent greater probability of consistent condom use. Talking about condom use resulted in men being twice as likely, and women being 59 percent as likely, to consistently use a condom in the last 6 months (OR = 2.07; CI $1.4-2.9)$.

${ }^{32} \mathrm{OR}=1.11 ; \mathrm{CI} 1.0-1.2$
} 


\section{Gender Norms}

SDSI helped change attitudes toward equitable gender norms. The results of the analysis in this general linear model reveal that, independent of the effect of the sociodemographic variables (e.g., sex, age, municipality, education), greater exposure to SDSI was significantly associated $(\mathrm{p}<.001)$ with maintaining higher gender index values (see Table 7) in all three survey years. It was also observed that the study population displayed changes toward attitudes of greater gender equity over the period involved, independent of exposure to SDSI.

\section{Table 7 Items in the Gender Index*}

- A girl who has had various partners is easy.

- Where there are children, it's first and foremost the girls who should help out with the domestic chores.

- It is important for women to be virgins when they get married.

- In the family, the women should take responsibility for the house and looking after the children.

- Men need sex more than women.

- Women have the responsibility for avoiding pregnancy.

- Men need to have another woman even when things are going well with their partner.

- Women who carry condoms around in their bags are easy.

* Each "no" answer contributed to a higher score. The higher the score, the greater the gender equity.

The average score of the gender equity index of the study population increased 20 percent between the first and third surveys. Having been exposed to SDSI was significantly associated with positive change in attitudes towards gender. It was also noted that the participants' municipality, schooling level, and age had individual effects on this change $(\mathrm{p}<.001)$ : Estelí, first and foremost, as well as León, had higher figures than Juigalpa; people with a university- or technical-level education produced higher totals than those with a secondary-level education, who in turn scored higher than those with a primary-level education or no education at all. The older age group displayed higher totals than the younger group. Using a "population attributable risks" analysis, the following can be estimated as attributable to exposure to SDSI:

- 22 percent of the young people who do not consider that "women who carry condoms in their bags are easy." This translates into 15,377 young people in the three cities who would not have held this opinion had it not been for the influence of SDSI.

- 17 percent of the young people who do not consider that "women have the responsibility for avoiding pregnancy": 12,128 young people in the three cities.

- 11 percent of the young people who did not consider that "it is the women in the family who should be responsible for looking after the house and the children": 7,326 young people in the three cities.

In the qualitative studies, violence against women was one of the serious problems identified in relations between men and women. Generally speaking, this kind of violence is attributed to machismo: 
They're [the men] machista around here; they beat up the women. If [women] complain, they give them a good beating and that's it. And after beating them, they say, "look, go and do such and such a thing for me, and if you don't, I'll give you another beating."

Qualitative study 2; male from control group ${ }^{33}$ in Estelí

We women very often open the way for that machismo, because if my husband tells me "you're not going to do this because that's men's business and you're going to stay home washing clothes, ironing," then that's what I do.

Qualitative study 1; female from Estelí; non-organized women

I think the ideal thing would be for the man to work and the woman to work less. In other words, if [the woman] dedicated more time to the family, you know, to things related to family values.

Qualitative study 2; male from control group in León

Those interviewed in the qualitative studies recognized SDSI's contribution on the issues of machismo and violence, which were addressed in the television series, radio program, and other activities. For young people who are linked with and representatives of organizations, SDSI's main contribution was airing the issue and providing tools and opportunities for local-level work on these subjects.

[Sexto Sentido deals with] subjects that aren't talked about in the family, the prejudices that exist in the family; sex and illnesses aren't talked about. A lot of things that were covered in the program aren't talked about.

Male focus group member; monitoring with Sexto Sentido Radio listeners and Sexto Sentido TV viewers, 2004

\section{Stigma}

SDSI helped bring about changes in attitudes toward HIV and sexual orientation that reduce stigma. However, certain attitudes toward people living with HIV or stigmatized groups proved more difficult to change.

\section{HIV-related stigma}

The results of the analysis in this general linear model show that, independent of the effect of the sociodemographic variables (sex, age, municipality, education), greater exposure to SDSI was significantly associated $(\mathrm{p}<.001)$ with the highest values in the stigma index (see Table 8$)$ in all three survey years. As with the gender index, the group as a whole displayed changes toward less stigmatizing attitudes over time. The stigma index rose by an average of 20 percent between the first and third surveys, indicating a reduction of HIV-related stigma over time.

\footnotetext{
${ }^{33}$ The "control group" was made up of young people who weren't associated with the panel study in any way.
} 
Table 8 Items in the Stigma Index*

- You would eat at the same table as someone with HIV.

- If a man is homosexual then he's to blame if he gets infected with HIV.

- HIV is a punishment from God.

- Prostitutes are to blame for HIV.

- You would feel ashamed if someone in your family were infected with HIV.

- You would be willing to be friends with someone infected with HIV.

* In this index, "yes" answers to the first and last question and "no" answers to the others contributed to a higher score.

The higher the score, the lower the stigma.

As in the gender index, in addition to the association with exposure to SDSI, there were differences according to the municipality, level of schooling, and age $(\mathrm{p}<.001)$. Estelí and León showed greater changes toward higher scores than Juigalpa; people with university level-education showed greater changes than those with secondary-level, who in turn displayed more than those with primary-level education or no education at all. The older age group showed a greater change than the younger one. The stigma index also reveals significant differences according to $\operatorname{sex}(p<.001)$, with more changes toward higher scores among women than men.

Analysis based on population attributable risks allows the following to be attributed to exposure to SDSI:

- 19 percent of those who said they would eat at the same table as a person with HIV. This translates into 15,673 young people in the three cities who would not have answered this way if it hadn't been for the influence of SDSI.

- 17 percent of those who said that prostitutes are not to blame for HIV: 9,856 young people in the three cities.

- 18 percent of those who said that people living with HIV should not feel ashamed: 15,597 young people in three cities.

- 18 percent of those who said they would be friends with someone with HIV: 13,901 young people in the three cities.

The qualitative studies also revealed a change toward less stigmatizing attitudes:

I know someone with HIV; I don't have a great deal of contact, but now I have more respect and I'm less afraid.

Qualitative study 3; young female from Bilwi

\section{HIV stigma related to homosexuality and sex work}

The questionnaire included various questions aimed at exploring stigma related to sexual orientation and sex workers. The statistical analysis revealed that while stigma decreased in general, there was a greater probability of a less stigmatizing attitude toward homosexuality among those most exposed to SDSI. In addition, the net change in attitude was greater among those more exposed to SDSI. Positive response to the idea of maintaining a friendship with a friend discovered to be lesbian rose from 38 percent to 48 percent ( 26 percent to 31 percent among less exposed), while in the case of a male friend 
discovered to be homosexual, the positive response rose from 36 percent to 49 percent ( 23 percent to 32 percent among less exposed, $\mathrm{p}<0.05$ ).

The population attributable risks analysis estimated that 20 percent of the young people who said they would continue being friends with someone who told them he was homosexual can be attributed to exposure to SDSI. In the three cities where the study was implemented, projections suggest the equivalent of approximately 16,249 young people with this attitude due to the influence of SDSI.

The data suggest that the greater acceptance of homosexuality could be limited to the private sphere, not extended to the public one. As mentioned, one of the items that changed substantially over time was whether "you would be friends with a homosexual." The same was not true, however, for the items "it would be fine for two homosexuals to live in the same house" or "people would accept it."

Generally speaking, while the qualitative studies revealed more positive attitudes and assessments of the general rights of all people regardless of their sexual orientation, a strong stigma prevails toward homosexuals and sex workers, who still tend to be blamed for the problem of HIV.

Above all [HIV/AIDS] affects homosexuals and prostitutes. A lot of people have been affected by this disease. I guess it's because they didn't protect themselves. They're people who don't measure the consequences of going around with one person, then another and don't take so many precautions.

Qualitative study 2; female from control group in Juigalpa

It is interesting to note, however, that the blame is attributed to the lack of use of protection, not to the identity of the person or group.

The first study revealed that the issues linked to homosexuality in the Sexto Sentido television series were very controversial. At the same time, there was a very positive assessment of the fact that SDSI addressed the issues of people living with HIV and prejudices in society against homosexuals. The questioning of those prejudices has generated changes in some people's attitudes to homosexuals and sex workers. For example, some of those interviewed felt that SDSI had helped them develop greater acceptance of homosexuals:

Before the series, people didn't think that gays and lesbians thought the same way as us, but now I know they're human. I feel great admiration for gays; they're brave. I used to find them repugnant; but not now.

Qualitative study 3; young female from Estelí

Those of us from the club met up to reflect on the series. When we saw the gay episode some of us started making fun of them, but it helped us to relate to people like that. It had an impact because, for example, they associate with homosexuals now.

Qualitative study 3; young male from Juigalpa 


\section{Knowledge and Use of Services}

The knowledge and use of centers that provide services related to HIV and domestic violence increased during the period in question and the statistical analyses indicate an association between this behavior change and greater exposure to SDSI.

\section{Knowledge of services}

In general, the study population's knowledge of the services available increased between the first and third surveys (from 54 percent to 64 percent for centers working on domestic violence, and from 61 percent to 74 percent for HIV-related services).

The logistical regression analysis for the dichotomous variable for knowledge of services (knows or doesn't know) $)^{34}$ revealed that exposure to SDSI increased the probability of knowing where to go in cases of violence against women or HIV. The following results are based on odds ratios with their respective 95 percent confidence intervals. Compared to the less exposed group, the group with greater exposure was: 33 percent more likely to know about a center dedicated to the problem of violence; ${ }^{35}$ 17 percent more likely to know where to take an HIV test $;{ }^{36}$ and had 30 percent greater probability of knowing where to go in response to concerns related to HIV or STIs. ${ }^{37}$ People in this group were also 23 percent more likely to know a center that would respond to concerns about sexuality. ${ }^{38}$

Knowledge of services differed according to gender. Women were 44 percent more likely than men to know a center with services related to violence but 11 percent less likely to know a center for consulting about HIV/STIs. The municipality and level of schooling also had an effect on knowledge of centers that provide HIV/STI-related services. A greater probability of such knowledge was associated with Juigalpa and with a higher level of schooling.

The second qualitative study revealed knowledge of the centers providing services related to HIV and violence. In all three cities, health centers and hospitals were the best known places for receiving services related to HIV, and the Women's Police Stations and the Ministry of the Family (MiFamilia) the best known for services related to gender-based violence. Other service providers were known in particular localities, particularly Ixchen (Estelí, León) and Profamilia (Estelí, Juigalpa).

The population attributable risks analysis reveals that the following can be attributed to exposure to SDSI:

- 23 percent of those who know a center that addresses cases of violence. This translates into 13,554 young people in the three cities who would not be aware of such a center if it were not for the influence of SDSI.

- 20 percent of those who know a center providing services related STIs/HIV: 14,635 young people in the three cities.

\footnotetext{
${ }^{34}$ For the logistical regression analysis, the category “doesn't know" included people who said they knew a center but couldn't remember its name.

${ }^{35} \mathrm{OR}=1.33 ; 95 \% \mathrm{CI}=1.19-1.47$

${ }^{36} \mathrm{OR}=1.17 ; 95 \% \mathrm{CI}=1.04-1.31$

${ }^{37} \mathrm{OR}=1.31 ; 95 \% \mathrm{CI}=1.18-1.46$

${ }^{38} \mathrm{OR}=1.23 ; 95 \% \mathrm{CI}=1.12-1.36$
} 
- 17 percent of those who know a center that addresses issues related to sexuality: 9,215 young people in the three cities.

\section{Use of services}

A general increase was observed in the use of services between the first and last measurements, although use of such services continued to be infrequent. Those most exposed to SDSI had a 48 percent greater probability of going to organizations or centers with concerns about violence ${ }^{39}$ and a 58 percent greater probability of going to an organization with concerns about sexuality (other than HIV).

There was no difference between men and women in terms of seeking services. There were, however, differences according to the city and level of schooling. People from Estelí were three times more likely to seek such services and those from León four times more likely than those from Juigalpa, and those with a technical- and university-level education 27 percent more likely than those with less education.

The population attributable risks analysis allows the following to be attributed to exposure to SDSI:

- 29 percent of those respondents who had been to a center providing attention for cases of violence in the last six months. This translates into 2,826 young people in the three cities who would not have gone had it not been for the influence of SDSI.

- 25 percent of those respondents who had been to a center to address issues related to sexuality in the last six months: 2,536 young people in the three cities.

According to the findings of the second qualitative study, failure to seek out services appears to be related to two main factors: incomplete knowledge of the services provided, and the fact that the centers are generally seen as curative centers for attending to illnesses, rather than places where one can obtain information and seek support and counseling. Although people know about the existence of such centers, they do not know about the kind of services they offer or the utility of those services.

I have heard of IXCHEN. [...] Here in Esteli I've heard that they help women there, ...I don't know how that works, I've never been, no...I've got very little information...

Qualitative study 2; female from Estelí; over-18 control group

I'd say maybe in PROFAMILIA; you could go there, because there's a lot of... a lot of people... because people go there to have examinations when they've got cancer; I've seen it. There are a lot of possibilities there for them to have an examination.

Qualitative study 2; female from control group in Estelí

\section{Knowledge of HIV and Risk Perception}

SDSI has helped improve general knowledge about HIV, its prevention, and important elements related to risk perception. This knowledge increased more among men than women. Meanwhile, the

$\overline{{ }^{39} \mathrm{OR}}=1.48 ; 95 \% \mathrm{CI}=1.2-1.9$ 
probability of considering oneself possibly at risk was greater among women in general and among members of the lower age group (both sexes) who had greater exposure to SDSI.

The study included a sizable set of questions on knowledge and behavior related to sexual life and the prevention of HIV. The one-on-one interviews also included general questions related to young people's risk perception.

\section{Basic knowledge of HIV}

Knowledge of HIV was generally quite high. For the purpose of this study, knowledge of HIV was evaluated through the statement, "it is possible to live with the virus for many years." The proportion of affirmative answers increased from 48 percent to 55 percent among the study population between the first and third surveys. Level of exposure to SDSI was positively associated with this knowledge, with the more exposed group 22 percent more likely than the less exposed group to respond affirmatively.

Regardless of exposure to SDSI, men had a 35 percent greater probability than women of responding correctly to this question.

\section{Knowledge of HIV prevention}

Knowledge of HIV prevention was evaluated by means of open-ended responses to the question, "how can a person prevent HIV?" The proportion that mentioned condom use during the first survey was high ( 80 percent), and rose to 83 percent in the final survey.$^{40}$ Exposure to SDSI was also associated with this increase, as the more exposed group had a 30 percent greater probability of answering "use condoms" than the less exposed group $(\mathrm{p}<.001)$.

Independent of exposure to SDSI, female participants were 27 percent less likely than male participants to reply correctly to this question. People from Juigalpa and León, the groups with lower schooling levels and the younger age group, were also less likely to provide a correct response to this question.

\section{Perception of individual risk}

Evaluating risk perception is intrinsically difficult due to the probable influence of various factors, such as knowledge of HIV prevalence, knowing one's own HIV status and the status of one's partner, condom use, and belief in individual and mutual faithfulness. The perception of risk was explored in a number of different ways, and while some of the results were encouraging, others raised some contradictions and additional questions.

\footnotetext{
${ }^{40}$ The last time this question was asked in a national survey of young men and women was in the 1998 ENDESA (Demographic and Health Survey), when 52 percent of women and 68 percent of men spontaneously mentioned condom use as a preventive measure. In the same survey, "abstinence" was mentioned by around 8 percent of both men and women, while 20 percent of women and 17 percent of men mentioned "limit number of partners."
} 
Personal risk perception or the personalization of risk was evaluated using the question, "Have you ever thought you could become infected with HIV?" If the answer was negative, the open-ended follow-up question asked "Why not?" One of the possible answers was "because I always use a condom." The answers "Yes, I have thought I could contract HIV," and "No, I haven't thought I could get HIV because I always use a condom," were analyzed.

Half of the sample (51 percent) responded that at some point they had thought they could become infected, with men 55 percent more likely to acknowledge their risk than women. A third of men and 40 percent of women said they thought they had no risk of becoming infected with HIV. ${ }^{41}$ While no changes in risk perception were observed over time among the sample as a whole, the data show an increase in young people thinking about their own personal risk of contracting HIV due to the influence of SDSI. Greater exposure to SDSI led to a 29 percent increase in the probability of answering, "Yes, I've thought I could get HIV." This effect was particularly pronounced among women with greater exposure, who were 35 percent more likely than less exposed women to acknowledge their risk.

Analysis according to age groups revealed that the probability of increased risk perception among the youngest people surveyed was 72 percent greater among the most exposed group compared to the lessexposed group.

In the step-wise analysis, personalization of risk perception was also linked to interpersonal communication about HIV and related issues. Those who had talked with someone about HIV and related topics were 51 percent more likely to have a sense of personal risk (67 percent more likely in men and 39 percent more likely in women).

At the same time, no association was observed between exposure to SDSI and other risk perception variables, including perceived level of risk. Perceived level of risk was ascertained with the question, "Do you think your risk level is high, moderate, minimal, or that you're not at risk?"

Analysis of the second qualitative study revealed that many respondents associate personal risk of contracting HIV with very remote events (such as being wounded with contaminated objects) rather than with sexual contact, which is the most common form of transmission in Nicaragua. The qualitative study also revealed the tendency for men to consider themselves without risk, or to not use a condom, because they trust their partner's fidelity. This could indicate the existence of knowledge of risk resulting from multiple partners, but a very limited personalization of risk.

I'm pretty sure I haven't got it, because you also have to know what kind of person you're going to have a relationship with, you know what I mean? And I only have relations with my partner and don't go out much on the street.

Qualitative study 2; male from control group in León

The women from the same study talked much more than the men about the possibility of acquiring HIV through sexual relations with their partners. However, this greater risk perception among women

\footnotetext{
${ }^{41}$ The only comparable data is the 2001 ENDESA survey of women, with 22 percent of young women saying they believed they were at risk of becoming infected and the 1998 survey in which 56 percent of men said they believed they were at risk.
} 
does not necessarily translate into preventative practices. Some women said they do not use condoms despite having mentioned the possibility of contracting HIV through their partner.

I'd say maybe, I might [become infected] because, perhaps, with me here and my husband working, who knows if maybe he's got another woman and she's infected? And maybe he'll come here and infect me.

Qualitative study 2; female from control group in Estelí

I'm with my partner, but you know that no man's faithful. I don't take precautions with my partner, of course, and I don't know if he'll go around with someone else.

Qualitative study 2; female from control group in León

In the qualitative studies, the people interviewed spoke of HIV as a problem, and of the impact of using Sexto Sentido to promote HIV prevention. SDSI has raised awareness in this respect, and in some cases fostered processes related to self-efficacy.

The process experienced by the young man with HIV had a real impact; it caught the attention of many young people and encouraged some of them to look for more information and take condoms to be distributed at high school. Some young people from all ethnic groups have started internalizing the need to protect themselves.

Qualitative study 1; young male from Bilwi

Personally speaking, it really helped me make decisions and clear up any doubts. For example, I really put the cards on the table with my partner about condom use.

Qualitative study 3; young female from Bilwi

\section{Communication}

SDSI exposure was associated with increased interpersonal communication about issues related to HIV and other topics, as well as communication with one's partner regarding prevention.

\section{Communication with other people about the issues included in SDSI}

This aspect of interpersonal communication was evaluated using the question, "Have you talked with someone about these issues in the last six months?" After receiving the responses, the issues were grouped in the following way for the purposes of analysis: 1) violence at home/sexual abuse/rape; 2) HIV; 3) homosexuality and lesbianism; 4) drugs and/or alcohol; 5) sexual relations/contraception/ abstinence/sexually transmitted infections; and, 6) the rights of young people.

The data from the surveys show a general increase in communication with other people, while the statistical analysis demonstrated that greater exposure to SDSI increased the probability of talking about any of the issues by 62 percent. ${ }^{42}$ Men, participants from León, and those with higher schooling

$\overline{{ }^{42} \mathrm{OR}=1.62 ; 95 \% \mathrm{CI}}=1.5-1.8$. 
levels had greater probabilities of communicating on these issues than women, participants from Estelí, and those with lower educational attainment.

Analysis using population attributable risk percents revealed that among those who said that they had talked to someone about one of these topics in the last six months, 21 percent can be attributed to greater exposure to SDSI. That is the equivalent of approximately 10,650 young people in the three cities who would not have had this kind of interpersonal communication were it not for the influence of SDSI.

The qualitative studies suggest that SDSI influences young people in their decision to talk about their personal problems with a person they trust, and to ask for help. One of the social goals of SDSI is to increase formal and informal dialogue and trust among people so they can talk more to each other and seek help within their networks of friends and family members. SDSI utilizes a number of different methodological tools and activities to this end. The annual SDSI youth camp provides a good example of this process.

[Camp] triggers personal-level changes, awareness-building, solidarity; it provides tools for personal and professional life. It's an experience that changes you, challenges your way of thinking....

Qualitative study 3; young male from Bilwi

On a larger and more public scale, the campaign "We need to be able to talk" was designed with the same purpose. In addition, Sexto Sentido TV serves as a means for disseminating information on different issues, encouraging people to talk more openly, and generating debate. Some young people also reported that the series promoted personal changes, got them involved, and facilitated dialogue with their families and friends.

At least it showed about AIDS there [on Sexto Sentido TV]. At least when Gabriel got infected it caught their attention. Some of us young people got talking about that.

Qualitative study 2; female from the panel study in Estelí

He watched the scene with the same problem with the family, brothers and sisters and all that, he says. It moved him, he says, and he started to cry and started to think things over, he says. And he told his friends; they were the first people he told, and they told him he was crazy, this, that, and the other, but he still had that doubt [...] whether what was happening to him happened to everyone. So he says that he'd never talked to his mum in his life, but that time he half talked to her. He says that he felt relieved, like a different person. Then he started trusting his mum more and she was helping him, telling him this and that. In short, he's managed to get off the drugs and says it was thanks to that program.

Qualitative study 1; local male advocate, Juigalpa

Interpersonal communication is linked to both individual behavior and to the more general social context and issues of public and private dialogue. As is discussed later in this report, interpersonal communication is closely associated with various aspects of sexual responsibility and HIV prevention. 


\section{Communication with one's partner about HIV prevention}

This topic was evaluated based on the responses of young people who said they had a partner, with "partner" being defined as someone considered to be a boyfriend/girlfriend, live-in partner, or wife/ husband, regardless of whether or not they were having sexual relations. The answers to the following questions were considered: "Have you talked to your partner about condom use in the last six months?" and "Have you talked with your partner about taking the HIV test in the last six months?" For the purposes of analysis, a variable was created for having talked to one's partner about one of these issues.

The longitudinal analysis reveals that the young people with greater exposure to SDSI maintained better levels of communication than less-exposed young people. Respondents with greater exposure had a 32 percent greater probability of talking to their partner about condom use and a 43 percent greater probability of talking to their partner about an HIV test, as compared with their less-exposed counterparts.

At the same time, the longitudinal analysis revealed a decreasing overall trend in participants (both with greater and lesser exposure to SDSI) reporting conversations with their partner about condom use. This percentage dropped from 41 percent in 2003 to 30 percent in 2005, with important differences by gender. Conversations reported by men decreased from 46 percent to 32 percent while those reported by women decreased from 37 percent to 28 percent. Similarly, the percentage of participants reporting conversations with their partner about getting an HIV test also decreased, from 19 percent in 2003 to 13 percent in 2005.

The downward tendency in the overall sample, not taking into account exposure to SDSI, was more marked in women, who displayed 39 percent less probability of having talked about prevention than the men. Also, the older age group of men and women had a 13 percent greater probability of having talked about prevention than the younger group.

A cross-sectional analysis comparing the baseline measure in 2003 with the final measure in 2005 regarding communication specifically about condom use reveals that while the level of communication with partners decreased among the non-exposed population, it increased among those exposed to SDSI. For men, the increase was from 29 percent at baseline in 2003 to 38 percent in 2005, while for women the increase was from 20 percent to 26 percent. Men who were not exposed decreased 3 percent, while women who were not exposed stayed at the same level.

Analysis using 'population attributable risks' shows that the following results can be attributed to exposure to SDSI:

- 23 percent of the young people who said they had talked to their partners about using a condom. This translates into 7,897 young people in the three cities who would not have done so without the influence of SDSI.

- 23 percent of those who talked to their partners about taking an HIV test: 3,104 young people in the three cities.

- 18 percent of those who have talked to their partner about previous sexual experiences: 4,423 young people in the three cities. 
The second qualitative study allowed the identification of certain factors that motivate or facilitate couples to talk about HIV. These include: 1) trust between the partners; 2) campaigns, reports, or programs broadcast by the communication media (including the Sexto Sentido television series, which was mentioned spontaneously) and printed informational materials; 3) participation in HIV-related activities; 4) perceiving that one's partner knows about the subject; 5) knowing about cases of people who have contracted HIV or are considered at risk or stigmatized (e.g., homosexuals); 6) fear of one's male partner being infected by other partners (only for women); and 7) having conversations with friends.

We saw things like that on the television, on Sexto Sentido, that kind of thing, so we started talking about it [...] I said, "Look, careful what you're doing." And she said, "Why are you saying that?" So I said, "Because I can see how those things play out on television, all that about AIDS, and it scares me."

Qualitative study 2; female from control group in Estelí

The same qualitative study also identified factors that reduce the possibility of talking to one's partner about HIV prevention. These include: 1) not considering it necessary because of previous conversations about the issues; 2) because communication is not always verbal ("talking"), but can also involve "implied understanding," reading the same informational materials about HIV, or even already knowing enough about the subject or one's partner's position in relation to it; 3 ) fear that "talking" might be interpreted as indicating unfaithfulness or distrust, especially if there has been a previous episode of unfaithfulness; or because it could be interpreted as an invitation for sexual relations when they have not yet been initiated; or because it is considered shameful or taboo to discuss; 4) general conflicts with one's partner; 5) lack of interest in the subject; 6) lack of time, due to work; and 7) because they have to see each other secretly, due to adult control.

He hardly spends any time with me. He spends all day working, from morning until late at night, by which time I'm asleep. Then the next morning it's the same again....

Qualitative study 2; female from the panel study in Juigalpa

We don't have time [to talk about the subject], because we're seeing each other in secret. [...]

We don't see each for very long at all. But I've got another brother who's got another house

down here, so when she's alone she goes there during the day... but just for two hours, one hour, real quick, we do what we're going to do and that's it....

Qualitative study 2; male from the panel study in Estelí

\section{Self-efficacy}

Although the tendency in the overall population was toward a reduction in the values of the selfefficacy index and the relationship power index, both of which are linked to negotiation of condom use, those most exposed to SDSI maintained higher levels for both indices. 


\section{The self-efficacy index}

Generally speaking, there was a tendency for the self-efficacy index (see Table 9) to fall among both the population with greater exposure to SDSI and the population with less exposure. The self-efficacy index fell by 3 percent of the initial value in the general population.

However, according to the general linear model and despite the general reduction, the group with greater SDSI exposure maintained higher values than the group with less exposure $(p=0.033)$.

Greater self-efficacy was positively and dynamically associated with greater communication with sexual partners regarding condom use, which led to more consistent condom use. This analysis is presented as part of the step-wise analysis.

\section{Table 9 Items in the Self-efficacy Index* (for negotiating condom use)}

- Would you be capable of correctly using a condom with your partner?

- Would you be capable of refusing to have sexual relations with your partner if he/she didn't want you to use a condom and you did?

- Would you be capable of refusing to have sexual relations with your partner if you didn't want to?

- Would you be capable of asking your partner to use a condom?

- Would you be capable of insisting on using a condom with your partner even if he/she didn't want to?

* "Yes" answers contributed to higher scores. The higher the score, the greater the sense of self-efficacy. The possible responses were: No, Yes, Don't know.

The qualitative studies revealed that people generally have a good appreciation of their capacity to take different measures to prevent HIV (use a condom, have just one sexual partner, keep informed and talk about the issue, take the test, etc). However, there was not much evidence that this is actually put into practice, perhaps because individuals do not consider themselves to be at risk or because they do not feel capable of negotiating condom use. Other factors here were the social norms surrounding sexuality and the stigma attached to certain preventative measures.

If I go to buy a condom, people are thinking about what I'm going to do, which makes me embarrassed about going to buy one [...] They say that only prostitutes use condoms. If I go buy a condom at the drug store they're going to think I'm a prostitute, even though I'm not....

Qualitative study 2; female from the study panel in Estelí

\section{The power and control in relationships index}

The second and third surveys measure the relationship power index (see Table 10), the extent to which the person feels that he or she has equal power and control in an intimate partner relationship. The tendency of the index values was similar to those for self-efficacy, with the index dropping by less than 3 percent in the general population over the course of the surveys. The general linear model revealed that the group with greater exposure to SDSI maintained the higher index values than did those with less exposure $(\mathrm{p}=0.025)$. 
Table 10 Items in the relationship power index*

- Most of the time you do what your partner wants to do.

- If you asked your partner to use a condom, he or she would think you were having sex with other people.

- When your partner and you are together, you're generally quiet.

- Your partner does what he/she wants, even if you don't want him/her to do it.

- You feel trapped or boxed in by the relationship you have with your partner.

- Your partner lets you wear any style of clothing.

- Your partner has more "say" than you in the important decisions that affect you both.

- When your partner and you disagree, she/he always gets her/his way.

- You are more dedicated to the relationship than your partner.

- Your partner might be having sex with someone else.

- Your partner tells you who you can spend time with.

- Generally speaking, your partner benefits more from or gets more out of your relationship than you.

- Your partner always wants to know where you are.

- If you asked your partner to use a condom, he/she would get really angry.

- If you asked your partner to use a condom, he/she would get violent.

* "No" answers contribute to higher scores. The higher the score, the greater sense of equal power and control in the relationship.

Independent of exposure to SDSI, women maintained higher levels for this index than men. People from Estelí and those with higher schooling levels also maintained higher values.

\section{Condom use and Other Prevention Behaviors}

The survey explored practices linked directly to coital sexual relations. Because of the possible sensitivity of some of the topics involved, they were mainly covered in the self-administered survey, which asked participants about condom use during their last sexual relations and the frequency of condom use during the previous six months. Adolescents and young people who said they had not yet had sexual relations were excluded from this analysis.

\section{Overall tendency of decrease in condom use with stable partners (not related to SDSI)}

There was as general reduction in consistent condom use with a steady partner (from 38 percent to 28 percent between the first and third surveys), and greater exposure to SDSI did not have a statistically significant direct association with greater condom use.

However, as is described in the step-wise analysis presented later in this report, SDSI did have an indirect role in promoting more consistent condom use through its positive impact on interpersonal communication, greater self-efficacy, and intimate partner communication about condom use.

The main reason stated for condom use with a steady partner was to prevent pregnancy. Among those who said they used condoms, the percentage reporting condom use to prevent pregnancy rose from 73 percent to 83 percent between the first and third measurements. 
The qualitative information allowed the identification of some of the reasons for steady partners not using condoms, including confidence in fidelity as a prevention measure and HIV-related stigma.

When you have a partner and you're married, it's not necessary; I don't think it's really necessary to use any other method. But with prostitutes, for example, I imagine that every time they're going to have relations with a man they ask him to wear a condom, because it's the best way, the best method of avoiding it, using a condom. And the same is true when men are unfaithful to their wives....

Qualitative survey 2; female from the control group in Juigalpa

When someone's a gadabout, going around in the streets, it's more of a risk, because they come across idle women, good time women. Meanwhile if you don't go out, you're alone at home, or if you have a wife and live with her at home, then you're less in danger.

Qualitative study 2; male from the study panel in Juigalpa

The quantitative studies measured the following sexual behaviors not related to SDSI:

- 30 percent of men and 15 percent of women said they had used a condom during their first coital sexual relation.

- The age at which young people had initiated their sexual life increased between the first and final measurements, with an average increase of from 14 to 15 years among men and from 16 to 17 years among women.

- There was a slight reduction in the number of partners in the 12 months prior to the first and last interviews, from 2.86 to 2.51 among men and from 1.30 to 1.17 among women.

- Based on the self-administered questionnaire, an increase in first sexual experience involving coercion was observed between the second and third surveys, from 14 percent to 16 percent. The questions explored how their first sexual relations had taken place, giving the options of "wanted to have relations," "obliged to have relations," and "did not want to have relations."

\section{Those most exposed to SDSI maintained their level of condom use with occasional partners, while the study population as a whole displayed a general reduction in condom use}

Generally speaking, the study population showed a tendency toward reduced condom use with casual partners. The prevalence of condom use with casual partners in the total sample fell from 55 percent to 50 percent between the first and third surveys. ${ }^{43}$ However, those respondents with greater exposure to SDSI were 44 percent more likely than their less exposed counterparts to report condom use during their last sexual relations with a casual partner, and 42 percent more likely to have "always" used a condom during the previous six months.

Women had 79 percent less probability than men of reporting condom use during their last sexual encounter with a casual partner. There were also differences according to the level of schooling, with

\footnotetext{
${ }^{43}$ The ENDESA survey didn't ask about steady versus casual partners, but rather distinguished sexually actively young people into the categories of those who are in steady live-in relationships ("in union") and those who aren't. The 2001 data for women reveals that 6 percent of sexually active young women used a condom in their most recent sexual encounter ( 5 percent of those in union and 11 percent of those not in union), while the 1998 data for men reveals that 30 percent of all sexually active young men used a condom during their last sexual encounter ( 7 percent of those in union and 45 percent of those not in union).
} 
people with technical- and university-level educations 2.25 times more likely to have used a condom compared to those with primary level schooling or no schooling at all.

The analysis by gender shows that men with greater SDSI exposure were 56 percent more likely than those with less exposure to have always used a condom in the last six months with a casual partner. No such difference was observed among women.

According to analysis based on population attributable risks, condom use by 18 percent of the young people who reported condom use in their last sexual relation with a casual partner can be attributed to SDSI exposure. This is the equivalent of around 2,500 additional young people in the three cities who would not have used a condom if it weren't for the influence of SDSI.

The qualitative approach revealed that some of the obstacles to condom use are rooted in a limited perception of risk, lack of information, and rejection (dislike) of condoms.

I only have relations with my partner. I wouldn't know how to protect myself with him because I never use condoms with him. But perhaps other people can protect themselves by using condoms....

Qualitative study 2; female from the control group in León

As I was telling you, condom use tends to be really annoying when you have relations. So I'd say that could be one of the problems with following the guidance when it comes to protecting yourself, because you tend to put your personal pleasure above everything else, before protecting your partner and protecting your own life.

Qualitative study 2; male from the study panel in León

\section{Social Capital and Collective Efficacy}

Evaluating collective processes and processes of social change involves multiple methodological challenges. As explained earlier, the quantitative component examined people's perception of their local context (social capital) as well as their sense of collective efficacy, understood to mean their perception that their immediate circles (friends, family members, barrio) could organize and implement collective actions related to HIV and domestic violence.

SDSI's impact on the local social context was analyzed using qualitative processes aimed to examine the relationship between processes of personal change and changes in the local environment. They also aimed to examine the possible links between the implementation of SDSI and effects triggered on the level of the local environment and collective processes.

For example, the second qualitative study revealed that although young people had greater knowledge of the rights of children and adolescents, and the right of women to live without violence, they also perceived that these rights are frequently violated with impunity. Respondents cited cases of domestic violence, sexual abuse, and adolescent pregnancy. The participants in the study criticized the communication media in general for not adequately covering the problems in their local social environment, with the exception of certain programs, including Sexto Sentido TV, Sexto Sentido 
Radio, and radio programs by local NGOs (all of which were mentioned spontaneously). They also recognized that getting involved in organizations enabled exercising the above-mentioned rights.

[T] he first time I was in a program for young people I felt pretty free to express myself. I could talk about what I wanted and what I felt.

Qualitative study 2; female from the panel study in Juigalpa

Results from the quantitative component revealed that the group most exposed to SDSI had an 11 percent greater probability of considering that their group of friends would be capable of "doing something together" to intervene in a situation of violence against women.

\section{SDSI promoted a favorable environment for the prevention of HIV}

The analysis was based on the perceptions of the following key actors: young people and adults from organizations, local health and social service providers, and people involved in local media. The analysis considered the perceptions of these key actors regarding the project's contributions to a favorable environment for HIV prevention.

The environment, or social context, was defined - particularly for the third qualitative study — as civil society's organizational arenas for forging alliances and promoting individual and collective actions. In particular, the analysis considered informal networks of individuals and organizations, including state institutions and communication media.

The study and the monitoring activities reveal SDSI's impact on processes. In particular, it measures how SDSI has contributed to gradual and diverse changes in local dynamics related to:

- Local work and the development of local initiatives

- Fostering dialogue and debate on taboo subjects in different social and cultural spheres

- Strengthening leaderships

- Collective efficacy

- Building links and alliances

At the same time, the conclusions of the study identified certain areas that require a more coordinated strategy with prioritized subjects, objectives, plans, and monitoring. This could allow SDSI to better capitalize on the rising awareness promoted by the mass communication component, in order to contribute to changes in the social context in a deliberate and structured way.

\section{Contributions to local work and the development of initiatives}

The project's contributions to changes in the social context are part of a set of initiatives developed on the local level to facilitate approaches, tools, information sharing, and debate on the issues of concern.

Due to the project's modality and the massive scope of the communication media, the different components have had a "trigger" effect in facilitating the work of the local organizations. Meanwhile, the training actions have allowed greater appropriation of the approaches, methodologies, and tools needed to work on these issues with different local population groups. 
We've coordinated workshops on sexual and reproductive health with Puntos. They've supported us in the training of the program's technical personnel and there's been an exchange of experiences. These workshops have allowed us to intensify our reflections and have provided us with methodologies.

Community advocate, female, from Juigalpa

We've been to Managua, where they've helped us reproduce these issues, and the materials they've distributed have helped in the training of young people and adolescents. They also gave us a DVD that's helped us explore the issues and approaches in greater depth.

Community advocate, female, from Juigalpa

The "We need to be able to talk" campaign and DVD methodological pack was widely accepted, and organizations affirmed it had encouraged the development of local activities.

In the last activity in the countryside we were expecting 45 people and 150 turned up! People liked the video, because it was like watching a movie and allowed them to internalize the message.

Policewoman, female, from Bilwi

Another activity that was appreciated was the posting of billboards publicizing Sexto Sentido TV and Radio, which also highlighted the names of local health and social service providers.

According to the interviews, the television and radio programs have provided guidelines and stimulated interest in continued attention to these issues. In Estelí, for example, a communication project coordinated by the youth network and Radio Cumiche reported they had adapted the materials from Sexto Sentido Radio to the local context.

Some local initiatives also incorporated the project's methodological approaches. The Youth Network in Estelí and a number of organizations in Bilwi (Tesis, Acción Médica Cristiana, the Anti-Drugs Commission, and the Bilwi Clinic) all held their own youth camps, for example. Some of these camps employed the SDSI manual and the "We need to be able to talk" package as methodological tools, and young participants from the SDSI camps served on the facilitating teams.

\section{Openness to dialogue and debate on taboo subjects in different areas}

As evidenced earlier, SDSI - and Sexto Sentido TV in particular - may have been a key element in transcending the public and private spaces, stimulating communication in both private arenas (family, friends) and public arenas (schools, organizations).

The mass communication activities in general seem to have made a significant contribution to the development of critical thinking about the issues addressed, generating opinions, breaking taboos, and stimulating dialogue and debate.

Sexto Sentido TV made a contribution because it got into the family, into high school, into work centers. It had a direct impact in those spaces.

Young female from Estelí 
When the program came out it was like a bombshell, seeing young people talking openly about taboo subjects [such as] menstruation and sexual relations. There was a lot of fear about touching on issues like homosexuality; even in the organizations the series generated much more openness for talking.

Young female from Estelí

\section{Increased dialogue in families}

Half of the quantitative study respondents reported that they watched the series with other people, with more than a third ( 38 percent) of those saying they watched "with the whole family." Combining these viewers with those who said that they watched with their mother or other members of the family, more than eight out of ten viewers ( 84 percent) who watched the series with other people did so in a family environment.

The qualitative studies revealed that, in addition to having a notable influence on the young people to whom it was directed, the Sexto Sentido television series often managed to involve the whole family, facilitating dialogue between parents and children on the issues addressed.

If the family sits down to see it, that generates debate and discussion, helps the mothers and fathers talk about issues. We love it; we never miss it.

Adult female from Estelí

\section{Increased dialogue with friends}

More than half the audience (61 percent) said that they had talked about the series with others. While the family ranks first as the company in which the series was watched, communication about Sexto Sentido was mainly with friends (80 percent).

Several subjects, like violence and AIDS, had a real impact on me. I'd talked about those issues but had never seen them as real as in Sexto Sentido. I've talked about those issues with my friends.

Young female from Juigalpa

Increased dialogue at high school

The tours and discussion sessions with the cast in several high schools in each city promoted spontaneous discussion on the issues covered in the series. Students spoke about the issues in the context of their own experiences. In some cases the issues were also debated with teachers in the classroom.

The issue of sexuality isn't mentioned at high school, but with Sexto Sentido it started to be talked about more openly. 
Increased dialogue in local organizations

Dialogue was developed both as part of various organizations' internal activities, and in their work with groups and communities.

After seeing these issues, we've discussed them in the [youth] commission, and they even left us a video to generate debate on the topic. There was a lot of participation. It made an impression on many people and helped them reflect on their own lives. Perhaps they were already experiencing some of the same things but didn't know what they were.

Youth commission member, female from Juigalpa

I use the materials from the series at the university to reflect with the students and generate debate. I also use them for training sessions with parents.

Community advocate, female from Juigalpa

Increased dialogue in the media

Individuals interviewed in the qualitative studies recognized that the issues addressed in the television series are taboo and therefore difficult to address using mass media. Similarly, journalists and others who work in local media recognized that that the radio program covers difficult and controversial subjects that are generally not dealt with by other radio media.

\section{Strengthening skills through training and exchange activities}

Training and exchange actions were aimed at strengthening the capacities of local organizations and media by helping develop skills among young organized leaders and communicators. The effects of SDSI were analyzed with the input of local leaders, to gauge their collective ability to incorporate issues and approaches of interest into the different arenas in the local environment (civil society and government).

In the interviews, young leader participants reported personal transformation processes that included changes in their personal values and attitudes, the development of useful technical skills and methodological approaches, and an increase in their own capacities to work in the local environment.

The third qualitative study, conducted after the end of the project in 2005, identified the following effects of SDSI on local leaders:

- It contributed to greater knowledge and a more in-depth examination of the targeted issues (gender, sexuality, HIV, sexual abuse, etc.).

- It facilitated the personal assimilation of different approaches (gender, generational, acceptance of diversity).

- It introduced methodologies for addressing the different issues.

- It strengthened technical and analytical capacities for social communication on these issues. 
In my particular case, going to the camp changed me. I thought only women should do housework and I was really sexist. I met more people at the camp, made friends with people from all over the country and learned that housework isn't just for the women, that you shouldn't tell boys just to play with cars or pistols, that men and women are equal.

Community advocate, male from Juigalpa

$H I V$ is a difficult subject. Just the exercise of imagining what it would be like having HIV was so strong it had a real impact on me.... Now I want to take the test and I want to tell everyone that it's important... I'd never thought about it before, but I do have sexual relations.... I don't know whether I'm living with the virus and I'd like to know... even though the idea frightens me....

2004 women's camp participant

Puntos has provided tools to awaken creativity and develop new capacities.

Youth network member, female from Estelí

The young communicators particularly referred to the technical and thematic training processes that have provided them with important elements to improve their development in their communication media.

More than just useful, they've been indispensable. I've learned to write scripts and what language to use.

Young communicator, Estelí

\section{Limitations identified}

Assessments of the training activities, particularly the youth camp, also revealed limitations to the practical possibilities of translating participants' experiences into tangible change in their organizations or communities.

All of the interviews highlighted the impact of the camp experience on the participants' lives and personal reality: it opened minds, promoted debates and exchanges, and created conditions conducive to personal changes. But at the same time, most of those interviewed mentioned experiencing a moment of real disorientation when they returned to their reality. In their own local communities they lacked the kind of social support that would help them consolidate their own personal changes. Many reported that they would have liked to receive more guidance on how to apply their new knowledge to influence the local and organizational reality in their environments.

It's like a dream being in the camp; then you come back down to earth; it's not easy maintaining that enthusiasm.

Camp participant, female from Estelí

After the camp comes a shock: a lot of confusion, frustration; it's even worse for the boys. There are no support networks.

Camp participant, female from Bilwi 
Another dynamic that limited young people's abilities to put their camp learning into practice was that upon returning from the camp they did not always have the backing of the adult leaders in their organizations (NGOs and health and social service providers) with respect to the issues and approaches addressed. Young communicators also reported resistance in the media in which they work. Participants also reported limitations due to lack of resources.

Despite these limitations, the qualitative evaluation suggests that SDSI provided important and varied contributions that, taken together, strengthen the work of different local actors and inspire young people. Overall, the different capacity-building modalities have helped consolidate a positive and significant increase in the number of young people with new ideas, capacities, and skills to influence the local environment. ${ }^{44}$

\section{Building links and alliances}

SDSI is designed to support and contribute to the work of organizations, media, and other bodies in reaching common objectives. It has therefore directed efforts toward developing and maintaining links and coordination with a wide range of community groups, governmental and nongovernmental organizations, health and social service providers, and communication media in the country's various departments.

The interviews with leaders and representatives of organizations particularly highlighted the suitability of Puntos de Encuentro's methodologies and materials for work on the local level. These methodologies and materials create common spaces for exchange and training. The interviews suggest that this has led to mutual recognition among participating individuals and groups, and has fostered communication and coordination.

On the local environment level, this has allowed consistent dissemination of key issues and approaches, as well as the distribution of the methodological packages and other materials that are used to raise awareness in the localities.

The establishment of the Radio Network and agreements with local cable TV stations has also been very important, facilitating the dissemination of Sexto Sentido radio and television to different Nicaraguan departments. It has also enabled the participation of young and adult radio professionals in the communication workshops.

The agreement signed with local health and social service providers resulted in a particularly positive assessment. The following factors were mentioned during a monitoring workshop with their representatives:

We've acquired a new approach for our work on sexual and reproductive health. Signing the agreement has fostered local recognition of the work we've done. The audiovisual materials have helped us in the workshops. The methodology has been shared in the workshops. New leaders have been formed. Puntos de Encuentro's publications have enabled us to project

\footnotetext{
${ }^{44}$ Puntos de Encuentro reports that it is taking these results into account in order to develop ways to solve some of these problems.
} 
ourselves outside of our own geographical departments. The establishment of new links has allowed us to sign agreements with other organizations and municipal governments. The agreement gave us greater representation in the municipal government structures.

Participants in a workshop with local representatives

\section{Limitations identified}

The third qualitative study revealed certain limitations in the way that alliances with local organizations were carried out during the 2002-2005 project period.

Perceptions and assessments in interviews with local leaders suggest that more systematic visits and communication between Puntos de Encuentro and local organizations would have been beneficial, to promote more dialogue and collective construction of initiatives and agendas.

Puntos provides the initiative: an issue or campaign. It coordinates and then disappears. It's not that we expect someone from Puntos to be around every day; we just want them to know how to better communicate with their allies, to work as allies, so we sometimes feel we don't have a voice or vote in relation to Puntos'agenda; we sometimes feel used.

Local leader, female from Estelí

The study found that the emphasis in the 2002-2005 project period on coordination and links with health and social service providers drained time and resources from youth groups and networks with whom Puntos had developed strong relationships over the years. This may have affected the involvement and strength of local-level leadership on issues related to the SDSI project. Young leaders pointed to a displacement of the youth groups and networks as the promoters of change in the local environment. They were also critical of the lack of continuity of Puntos' local-level presence.

In addition, the third qualitative study revealed that the definition of "alliance" for the purposes of the project was unclear to many participants. Many respondents felt that the community alliance intended to build an implementation strategy and guide implementation of the project was not inclusive enough, and was not characterized by sufficient collective decision-making. Respondents suggested that the inclusiveness and collaborative nature of the alliance was diluted by bilateral coordination and specific agreements, such as the distribution of materials produced by Puntos de Encuentro. ${ }^{45}$

\footnotetext{
${ }^{45}$ On the basis of this study and other reflections, Puntos de Encuentro reports they are re-thinking their strategies and operational plans in this regard.
} 


\section{More on Impact: Two Methods of Analysis Reveal SDSI's Impact}

\section{SDSI's Indirect Relationship to Condom Use: A Validation of SDSI's Conceptual Framework}

The step-wise analysis methodology was used to increase understanding of SDSI's role in triggering prevention-related behavioral changes (e.g., to measure the indirect relationship between SDSI and behavior change), and to test the conceptual model on which the strategy and project are based.

As discussed previously in this report, the results over time reveal a general reduction in consistent condom use over the three surveys, and exposure to SDSI was directly associated only with condom use in the most recent sexual relation with a casual partner.

However, using SDSI's conceptual framework to further analyze the various elements affecting condom use, step-wise analysis was used to explore relationships with other variables that - controlling for gender, age, and educational level — might have acted as intermediate triggers that would result in more consistent condom use.

A series of logistical regressions based on the final (2005) survey explored the possible associations among the exposure variable, intervenient variables (interpersonal and intimate partner communication, risk perception, and self-efficacy), and results variables (condom use with steady and casual partners, respectively) (see Box 3).

The relationships were analyzed for four dichotomous variables related to this behavior, all of which were included in the self-administered questionnaire. Variable analysis was done on both condom use during most recent sexual relation and

\section{Box 3 Summary of the analysis}

Independently of gender, age, and education level, exposure to SDSI is associated with increased interpersonal and couple communication on issues relevant to HIV prevention. Interpersonal communication increases individual riskperception of contracting HIV and increases perception of self-efficacy, or the ability to effect change in one's behavior or the behavior of his or her partner. Interpersonal communication has particular effects on women, who are three times more likely to perceive self-efficacy when they engage in communication. (Men who engage in communication are two times more likely to perceive self efficacy, as compared with men who do not engage in such communication.) The sense of self-efficacy is a particularly strong trigger for actually talking to one's partner, especially for women, who are five times more likely to actually speak with their partner about prevention when they perceive self-efficacy. Talking with one's partner is, in turn, associated with reporting having actually consistently ("always") used condoms over time.

Two interesting results are worth highlighting: there is a stronger link between communication and condom use with steady partners among men, condom use with casual partners among women. In addition self-efficacy itself-the sense that one is capable of talking about condom use with their partner-was not directly associated with reporting of consistent condom use. That relationship is mediated by actually having talked to one's partner. but a stronger link between communication and 
consistency of use during the last six months. Condom use was measured by the question, "How often have you used a condom when you had sexual relations with your steady partner during the last six months?" This variable was dichotomized, with the answer "always" representing the preventative behavior, in contrast to the other options (most of the time, sometimes, seldom, and never). The frequency-of-use variables were taken from the self-applied questionnaire to ensure a greater level of reliability and rigor.

Although the associations were stronger in the models constructed on condom use during the most recent sexual relation, because HIV prevention requires consistent condom use over time, this section presents the models constructed using as the results variables "consistent condom use over the last six months" with a steady partner and with a casual partner.

The step-wise analysis revealed a reinforcing feedback loop with respect to communication and condom use. Respondents with greater exposure to SDSI were 41 percent ${ }^{46}$ more likely to report interpersonal communication on the issues of interest, as measured by "having talked to someone in the last six months" about the issues addressed by SDSI, such as HIV, sexuality, violence, rights, and others. ${ }^{47}$ Interpersonal communication corresponds to a 51 percent increase in personal riskperception, as measured by the question, "Have you ever thought that you could contract HIV?", 48 and a 100 percent increase in the probability of perceiving self-efficacy, as measured by the question, "Would you be capable of asking your partner to use a condom?"

Perception of both personal risk and self-efficacy were in turn positively associated with intimate partner communication regarding prevention, as measured by the question, "Have you talked to your partner about condom use during the last six months?" Perception of personal risk increased probability of intimate partner communication by 62 percent, ${ }^{49}$ while perception of self-efficacy for requesting condom use more than tripled the likelihood of intimate partner communication. ${ }^{50}$ (Greater exposure to SDSI also directly increased the probability of intimate partner communication about condom use by 39 percent). ${ }^{51}$

Finally, intimate partner communication is directly associated with increased probability of condom use with steady and casual partners. The probability of reporting the preventative behavior - consistent condom use - with a steady partner was 82 percent greater among those who reported having talked to their partners about this particular issue, ${ }^{52}$ with important differences between men and women.

The relationship between partner communication and condom use was also demonstrated with respect to casual partners. This was measured by the question, "Have you used a condom when you had sexual relations with a casual partner during the last six months?" Respondents who said they had talked to

\footnotetext{
${ }^{46}$ This analysis is based on the final survey. The longitudinal analysis revealed a 62 percent greater probability of interpersonal communication. While these results are not comparable, it does highlight that different forms of analysis — all controlling for demographic factors such as age, sex, and educational level - independently reveal significant associations between exposure to SDSI and greater interpersonal communication.

${ }^{47}$ Variable $815 ; \mathrm{OR}=1.41 ; 95 \% \mathrm{CI}=1.2-1.6$

${ }^{48}$ Variable $\mathrm{N} 23 ; \mathrm{OR}=1.51 ; 95 \% \mathrm{CI}=1.3-1.7$

${ }^{49} \mathrm{OR}=1.62 ; \mathrm{CI}=1.4-1.9$

${ }^{50} \mathrm{OR}=3.57 ; \mathrm{CI}=2.7-4.8$

${ }^{51} \mathrm{OR}=1.39 ; 95 \% \mathrm{CI}=16-1.67$. Again, as with interpersonal communication, the longitudinal analysis revealed a stronger association.

${ }^{52} \mathrm{OR}=1.82 ; 95 \% \mathrm{CI}=1.4-2.4$
} 
their partners about this issue during the same period were 63 percent more likely to report having always used a condom with a casual partner during the last six months. ${ }^{53}$

As shown in the Figure 9, stratification according to sex (and controlled for age and education) revealed important differences between men and women. For example, the probability that exposure to SDSI would lead to interpersonal communication was greater among men (57 percent, compared to 29 percent for women). Men were also more likely to perceive personal risk as a result of SDSI exposure, with the probability of personal risk perception due to exposure increasing by 67 percent for men and 39 percent for women. Men were also more likely than women to translate their perception of personal risk into actually speaking with their partners about condom use, and men were 68 percent more likely and women 57 percent more likely to consistently use condoms with their steady partner as a result of intimate partner communication.

Other triggering effects were more apparent in women than men. For example, women who had talked to someone about the issues included in SDSI were three times more likely to say they felt capable of proposing that their partners wear a condom, as opposed to an 85 percent greater probability among men. And women who considered themselves capable of proposing condom use to their partners were five times more likely to actually talk with their partner about using a condom, while men in this category were three times more likely to do so.

Both men and women who had talked to their partners about condom use during the last six months were more likely to have consistently used a condom with their steady partner during that same period, with men twice as likely (OR 2.07; CI: $1.4-2.9$ ) and women 59 percent more likely (OR 1.59; CI: $1.1-2.3$ ). With casual partners, however, the differences according to sex were very different: women who had talked with their partner about using condoms were three times more likely to report having consistently used a condom with casual partners in the last six months, while the difference was statistically insignificant for men.

This analysis demonstrates that Somos Diferentes, Somos Iguales effectively encourages processes of interpersonal communication, which in turn favors communication among couples and the assimilation of preventative behaviors. By showing the dynamic relationship between attitudes, perceptions, communication, and behaviors, the model offers important insights for working on issues that involve intimate aspects of people's lives such as sexuality, and validates the conceptualization of SDSI as a strategy that fosters a more favorable environment for HIV prevention by triggering social and intimate communication processes.

$\overline{{ }^{53} \mathrm{OR}}=1.63 ; 95 \% \mathrm{CI}=1.2-2.3$. 


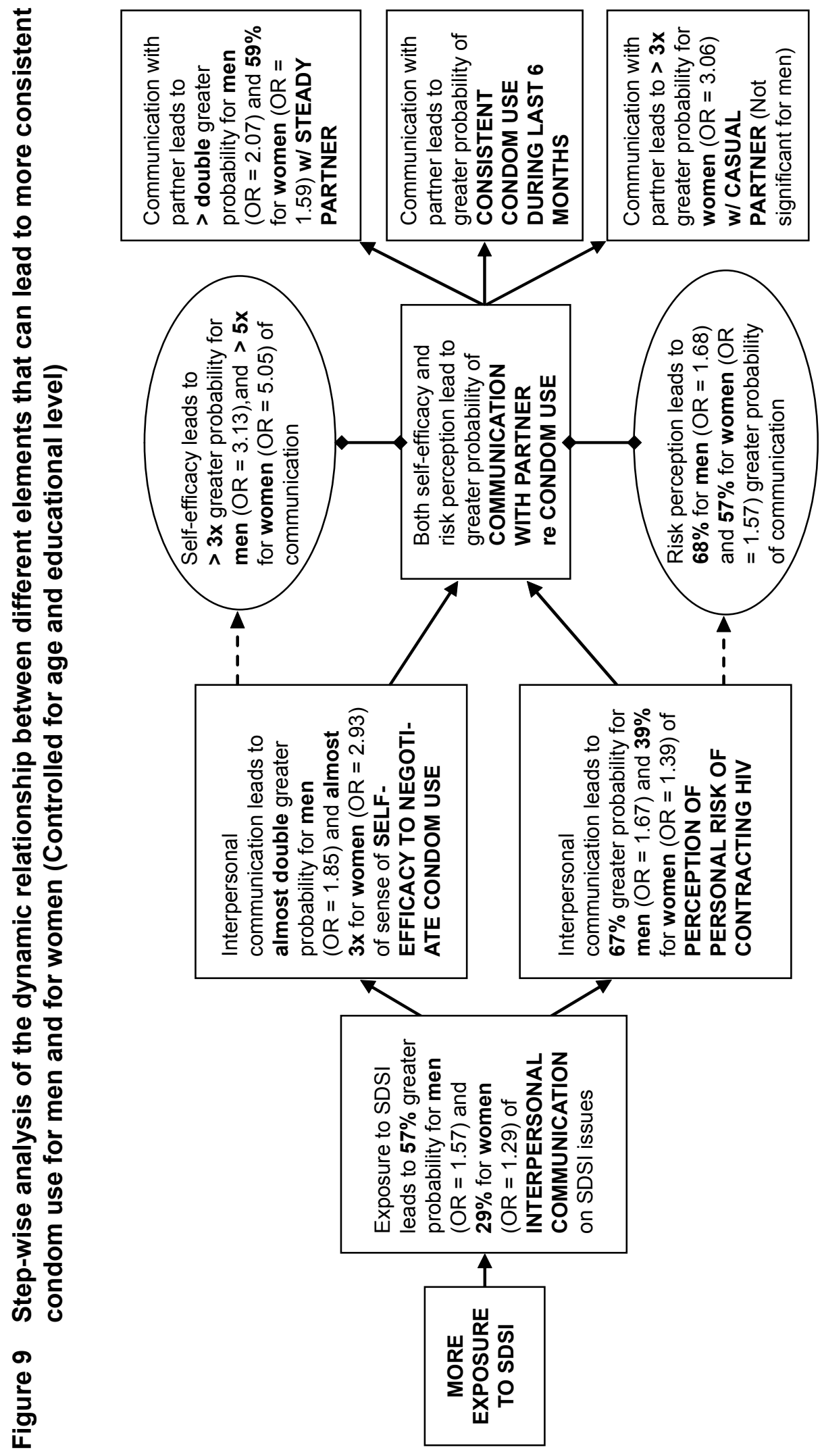




\section{Entre Amigas: An Example of Analysis of the Synergistic and Net Impact of Sexto Sentido in 10-14 Year-Old Girls}

Entre Amigas was an inter-institutional ${ }^{54}$ project that focused on the empowerment of 10-14 yearold girls in the working class municipality of Ciudad Sandino near Managua. The intervention combined peer education, the strengthening of support networks, and the Sexto Sentido TV series. The quantitative research team for the evaluation of the project was the same as for SDSI.

The evaluation of Entre Amigas (which translates as "among friends" in the feminine form of the noun) used a baseline and post-intervention surveys to measure changes. The kinds of changes sought by Entre Amigas and by SDSI were similar, and the evaluation revealed significant changes in several of SDSI's objectives: the girls' gender vision, their sense of self-efficacy, and their perception of the risk of STIs/ HIV/ AIDS.

Part of the impact analysis involved an exercise to determine the "net impact" of the different components in the Entre Amigas project, as well as their synergetic effect. It aims to identify, distinguish, and compare the net impact of the intensive interpersonal work of the peer education component of the project (being part of a group of "friends") and exposure to the mass communication intervention of the Sexto Sentido television series. It also measures the combined impact of the various components.

The analytical exercise was carried out using the "self-efficacy" variable. In the case of Entre Amigas, this variable was defined with respect to the girls' self-assertiveness: that the girls affirm that they don't believe it's their fault if they're treated badly, and that they do have the right to speak out if something is bothering them.

Independent of any other factor or influence, the girls who had participated in a group of "friends" had a 73 percent greater probability of being self-assertive. If both they and their mothers had participated, the probability was 91 percent greater. And if they and their mothers had participated and they also watched Sexto Sentido, they had a 122 percent greater probability of being self-assertive.

Out of every 100 girls who responded in a self-assertive manner, 15 can be directly attributed to the combination of all three activities. Taken separately, seven can be attributed solely to exposure to Sexto Sentido, and nine to having been part of a group of friends, These results show that Sexto Sentido made a substantial contribution to the project's global impact, almost matching the level of net impact achieved by the much more intensive community work, but with much greater reach and much lower cost-impact ratio.

\footnotetext{
${ }^{54}$ PATH coordinated the project, which was implemented in 2002-2004. The Center for Studies and Social Promotion (CEPS) implemented the community and peer education component in Ciudad Sandino; and Puntos implemented the mass communication component (Sexto Sentido), whose reach extended beyond Ciudad Sandino to the rest of the country. CIDS/UNAN-León and other consultants implemented the project's impact evaluation with quantitative and qualitative studies both before and after the intervention.
} 


\section{Discussion and Reflections about the Results and Their Implications}

The challenge of containing the HIV epidemic requires joint and committed action from multiple social actors. The results of this impact study demonstrate that the implementation of a multimedia and multi-level strategy encouraged processes of change on both the individual and collective levels and that the project fulfilled its main objective of contributing to national prevention efforts.

\section{Large-scale Impact}

Given the massive reach of the intervention, the results demonstrate that SDSI has made a very large-scale contribution in key aspects of HIV prevention. In both longitudinal and cross-sectional analysis, "greater exposure" to SDSI was significantly associated with changes in a series of indicators measured among the same population of adolescents and young people in three municipalities with different characteristics over a three-year period.

The analysis and results regarding changes associated with "greater exposure" to SDSI apply to 59 percent of the population interviewed. Based on population projections for the urban adolescent and youth population of Nicaragua, the changes could have affected more than 700,000 adolescents and young people, a third of the entire adolescent and youth population of the country. ${ }^{55}$ This means that even when the percentages or proportions related to certain changes are relatively small, those changes affect a large number of people. PAR analysis allowed estimates of the number of adolescents and young people whose changes over time could be attributed to greater exposure to SDSI.

In addition, Sexto Sentido's reach, scope, and popularity - as well as the fact that people exposed to it mentioned watching it with other people and reported greater communication with others about the issues of interest - make it highly probable that the program had a much wider influence than indicated by the simple variable of "greater exposure to Sexto Sentido." By fostering more open communication on these issues, SDSI has possibly contributed to changes among young people who did not watch the program but did participate in discussions with other young people who had greater exposure to the program.

\section{Impact on Complex Processes}

Individual behaviors (e.g., consistent condom use in sexual relations) are not isolated from the environment in which people live, but are rather related to social aspects and processes. The evaluation

\footnotetext{
${ }^{55}$ Given that the survey samples were representative of the urban adolescent and youth population in each of the three municipalities, it's possible to project that these changes affected some 55,000 young people between 15 and 24 years old in the three municipalities, and 105,000 between 10 and 29 years old. The urban youth population in these three municipalities represents 15 percent of the national urban youth population, and although the study sample was not representative nationally, based on 59 percent having been "more exposed," it is possible to make a conservative projection of 380,000 urban 15-24 year olds and 730,000 10-29 year olds nationally. This is the equivalent of 33 percent of the total youth population (urban and rural) of the country in these age groups, or 14 percent of the entire population of Nicaragua.
} 
results and their analysis reveal the complexity and the dynamics of links between subjective, personal, interpersonal, and environmental processes. The study's findings highlight as key elements processes of interpersonal communication on general or specific subjects related to prevention practices. They also validate the conceptualization of SDSI as a strategy that fosters a more conducive environment for HIV prevention by influencing these subjective and communication processes.

One particular result validates the conceptual framework of both the intervention and the evaluation. In this case, greater exposure to SDSI was associated with greater interpersonal communication, which encourages perceptions of personal risk and self-efficacy that in turn lead to a greater probability of concrete actions, such as talking with one's partner about prevention (also associated with SDSI). And this ultimately results in a greater probability of consistent condom use.

\section{Gender, Age, and the Passage of Time}

Besides level of exposure to SDSI, the most significant variables to affect program results were gender, age, educational level, and the passage of time. The second qualitative study explores how the "natural" maturing process leads to changes in young people's perceptions and priorities as they acquire more experience and more responsibilities.

The important differences in results for men and for women point to the need to better understand what is happening beneath the discourse of greater gender equity. While the overall sample moved in the direction of greater equity in gender norms, this doesn't seem to have resulted in significant changes in sexual norms that are also greatly affected by gender relations. The change in discourse is positive in itself in that it signals a change in what is considered socially acceptable. However, the more intimate manifestations of gender inequities — such as in sexual relations - will probably take much longer to change.

In general, the significant differences in men and women in some of the key results point to the continuing need to have a very clear gendered focus for work with young people on issues involving relationships and sexuality. Given the overall tendencies over time, it would be useful to further explore the links between gendered power and control issues in relationships with intimate partner communication and practices.

It is also interesting to note that a separate study of Sexto Sentido, using an anthropological approach to understand how audiences understood gender issues in the TV series (Rock 2005), discovered that viewers actively engage with and interpret the meanings of the stories through the filter of their own lived experience, which very rarely coincides with the kind of "gender" or "rights" discourse and indicators used by researchers and NGOs. Both this and the findings presented in Puntos' companion descriptive report, Expectations and Realities: Nicaraguan youth navigate gender, sexuality, HIV and more, highlight the need for further exploration about how young people understand the gendered nature of their own experience in order to better address the issues involved. 


\section{The Relative Lack of Use of Health and Social Services}

The conventional wisdom has been that health and social services can be an important source of support for young people and have a positive effect on promoting healthy behaviors. However, both the quantitative and qualitative data revealed that despite awareness of available health and social services, there is a low level of use of those services. On the one hand, there is an apparent lack of clarity of the range of support services available, and on the other, there is a certain stigmatization attached to acknowledging the need for such services. In addition, there is a perception that services are only for people who are sick or in trouble. Further research and analysis are required to better understand the apparent disconnect between knowledge of services and use of them, and to better understand young people's concerns in order to re-think the role of health and social services as part of a social support infrastructure. Finally, further research and analysis is needed to re-think the meaning of "accessible" and to examine more carefully the way services are promoted in the community. The demonstrated importance of interpersonal communication suggests that perhaps a less formal and more interpersonal approach might be appropriate.

\section{Prevention as Maintenance Over Time}

The data revealed overall tendencies that point in different directions. There is evidence that certain aspects of the environment have become more favorable for HIV prevention and that SDSI has had a positive impact: Young people reported more equitable gender norms and less HIV-related stigma in 2005 than in 2003. In addition, although not associated with SDSI, there was a slight increase in the age of first sexual relations and a slight reduction in the number of sexual partners during the previous 12 months.

However, other important indicators displayed a tendency toward a less favorable environment. For example, there was a general "worsening" of the overall perception by young people of their local social context and a decrease in young people's sense of collective efficacy to solve problems. The qualitative studies revealed that although young people perceived greater knowledge of the rights of children and adolescents and the right of women to live without violence, they also perceived that these rights are frequently violated with impunity. There was a general decrease in young people's sense of their own self-efficacy to negotiate their sexual relations, a decrease in intimate partner communication, and indeed, a decrease in consistent condom use with both steady and casual partners.

In a context of both increasing HIV prevalence and a more adverse context for prevention, the positive impact of SDSI in maintaining levels and/or stemming the decline in several important variables can be seen as an important contribution to prevention efforts.

\section{The Importance of Interpersonal Communication}

The issue of interpersonal communication as key to other processes is an important consideration for the design of interventions that hope to impact complex and intimate issues such as sexuality. The step-wise analysis demonstrates a positive association between interpersonal communication and risk perception, self-efficacy, and consistent condom use. This suggests that the process of communication 
with one's partner is key among those who reported consistent condom use with steady partners and with casual partners. In an adverse context, promoting more openness in communication seems to have a positive effect.

This is even more relevant in the case of women who feel able to talk to their partners about condom use, which is in turn associated with effectively communicating about the issue and finally with practicing condom use. At the same time, SDSI itself appears to have greater specific impact on men engaging in interpersonal communication, perhaps because women in general communicate more than men.

Given that intimate partner communication decreased over time (mitigated by SDSI's positive impact), it would be useful to further explore the possible links between the perception of the social context and its potential influence on openness in intimate partner communication on prevention issues.

\section{The Question of "Pre-disposition" and/or "Self-selection"}

Several of the results reveal a tendency that those who were identified as part of the "more exposed" group demonstrated higher values not only at the end of the study, but also at baseline in several indices such as gender equity and stigma. Participants were categorized at the end of the study, based on their responses over time. It could be argued that this could mean that those who watched Sexto Sentido TV more regularly (the more exposed group) were, in effect, predisposed to the kinds of changes that were detected as being attributable to greater exposure to SDSI.

An independent analysis of the pre-disposition issue ${ }^{56}$ detected that although those who were in the "more exposed" group and those that named Sexto Sentido as one of their favorite locally-produced shows did in fact demonstrate higher values at baseline in some of the variables related to issues of stigma, discrimination, and equity, they did not necessarily demonstrate higher values in all areas at baseline. In addition, the results also show significant changes among these more regular viewers.

Another interesting result is that the overall sample generally reported that they felt their own views on issues such as stigma and discrimination were more "progressive" than those of their peers. In this light, it's possible that for those viewers who may have been "pre-disposed" to agree with some of the views put forth in Sexto Sentido, the series played a role in reinforcing what they themselves considered minority views, providing support for the kind of thinking that goes against the perceived social norm.

It is also interesting to note that religiosity — which could be considered relevant to attitudes toward many of the issues addressed by SDSI - was not a relevant factor in terms of the Sexto Sentido audience; that is, the "more exposed" group was equally religious as the "less exposed" group.

\footnotetext{
${ }^{56}$ Carried out by Brian Linneker and Dr. Sarah Bradshaw, Senior Lecturer in Development Studies, Middlesex University, England. Dr. Bradshaw evaluated the 2001 phase of the SDSI project.
} 


\section{Reaching and Impacting Different Groups within the Adolescent and Youth Population}

Although it would require a different kind of analysis than was carried out for this evaluation, there is evidence to suggest that Sexto Sentido possibly had more impact in the sectors of the youth population that began with the lowest values in many of the indicators: men in general (as opposed to women), the younger population of 13-18 years (as opposed to the 19-24 year old group), and in Juigalpa (considered the most conservative of the three municipalities, and the one with the least number of organizations and health and social services). It was also observed that Juigalpa, the municipality with less other entertainment/recreation options than León and Estelí, had a higher regular viewership than the other two municipalities.

While the endpoint values for the groups mentioned above were not as high as for other groups, there is evidence to suggest that there may have been a bigger net change in these groups in some important variables. In addition, there might have been a bigger net change in the larger sub-group of the more exposed population that watched the series "occasionally," as opposed to the smaller sub-group that reported they watched the show "almost always."

If this were true, it would point to the importance of mass media "edutainment" interventions like Sexto Sentido for impacting on different sub-sectors of the population, and especially in places where there are fewer activities of other kinds being carried out.

\section{Cost-effectiveness of SDSI}

A cost-study carried out by PATH as part of the evaluation of the "Entre Amigas" project revealed that the cost per adolescent/young viewer of Sexto Sentido in Nicaragua was roughly US\$0.04 per episode, or US $\$ 0.60$ per season (15 episodes). The cost per viewer for the three seasons between 2003 and 2005 works out to roughly US\$1.80. Compared to other kinds of interventions, Sexto Sentido is a very cost-effective way to reach and effect change in a large number of people.

Given that over half of those who watched the series did so with other people, many of them with "the whole family," the cost efficiency could be even greater, assuming impact on other population groups. The evaluation of the Entre Amigas ${ }^{57}$ project for example, revealed that Sexto Sentido had an important net impact in its own right in 10-14 year-old girls, and an even greater impact interacting with actions related to peer education and strengthening of support networks.

The value of the investment in the TV series has been further enhanced by the series' broadcast on both open TV and cable channels in other countries in the region, substantially increasing the project's scope and impact. In addition, special thematic editions of the series are converted into methodological packages (DVDs with discussion guides) for local use with young people, and demand across the region has been high, with the packs being used by local groups and organizations in Central and Latin America. ${ }^{58}$

\footnotetext{
${ }^{57}$ The project was developed in collaboration with PATH and the Center for Studies and Social Promotion (CEPS). The SDSI mass communication component formed part of the project in a collaborative relation.

${ }^{58}$ Methodological packs include videos and discussion guides on HIV, sexual abuse in the family, machismo in daily life, emergency contraception, growing pains of puberty, and breaking cycles of violence at home and in young couple relationships.
} 


\section{Reflections on the Study's Methodology}

\section{Rigor and Reliability}

The study was notable for its scientific rigor and the complexity of its approach and analysis. SDSI's multi-study, quanti-qualitative evaluation model allowed the determination of cause and effect associations and the proposal of explanatory models within a multi-level approach. Very few studies in the field of social communication have been so rigorously implemented. In this sense, the study's results represent an important contribution to international literature on the effectiveness of this kind of program.

One of the panel study's main strengths is that it interviewed the same young people over a three-year period, measuring their processes of change in relation to the issues of interest. This design allows changes attributable to the intervention to be identified with far greater precision than in the case of "pre- and post-" intervention cross-cutting studies, as it permits the analysis of changes on the individual level and is not just limited to comparing groups of people.

Other strengths of this particular study include the high response rate, the acceptable rate of participants "lost-to-follow up" over the three years, the reliability of the responses as demonstrated by statistical tests, and the multivariate statistical models that allowed the isolation of the effect of sociodemographic variables.

\section{The Hawthorne Effect}

Analysis in the field of quantitative research has shown that study panels (with repeated measurements) can generate their own effects on the participants, something known as the Hawthorne effect. These effects include the possibility that participating in the study will encourage the participants to give more "socially desirable" responses in subsequent rounds, suggesting "changes" that do not really exist. Another possible consequence is that while the changes may be real, they are not derived so much from exposure to the intervention as from the reflection triggered by participation in the study itself.

Analyzing this in relation to the current study, the researchers note that since all of the participants started the study under the same conditions (i.e., they had no exposure to any of the three seasons of Sexto Sentido contemplated in the project), the effect of participating in the study itself could explain why both people who were less exposed to SDSI and those who were more exposed displayed positive attitudinal changes over time.

In this sense, any effect produced by participation in the study would have the effect of reducing the differences between the groups with lesser and greater exposure. If that's the case, it is possible that the SDSI-associated impact may have actually been greater had it not been for the Hawthorne effect. 


\section{Methodological Challenges and the Need for Many Different Approaches}

The results presented here are just the main findings that permit identifying effects attributable to the SDSI communication strategy. In terms of the potential for understanding social changes and HIV prevention, there are many, many possibilities for future analysis using the database resulting from the study.

Several decades of research have produced a great deal of evidence on the impact of the use of communication media on sexual behaviors to regulate fertility and on the dissemination of information as a factor that influences contraceptive use (Westoff and Rodriguez 1995; Jato et al. 1999). There is less evidence of the impact and efficacy of multimedia interventions in relation to HIV prevention. SDSI had an impact on important change processes related to HIV prevention among this population. The results of this study complement the growing number of studies and revisions that have demonstrated the possible impact of using communication media in the field of sexual and reproductive health, including HIV prevention (Bertrand and Anhang 2006; Bertrand et al. 2006; Cochrane Collaborative Review Group on HIV Infection and AIDS 2004).

Much remains to be explored in relation to the evaluation of communication programs. As mentioned above, the effectiveness of communication actions would be enriched by analyzing how that impact has gestated and developed, rather than limiting the evaluation to "measuring" the impact (among viewers, for example). This requires different approaches. For example, more in-depth analysis of the interventions based on the conception of active audiences is required to understand how they respond to the dissemination of messages, how ideas position themselves, and how audiences "negotiate" meaning according to their own beliefs, attitudes, and social norms, which are either similar to or contradict the perspectives introduced by the intervention. More studies using anthropological approaches (such as Rock's approach, mentioned above) would allow a more nuanced understanding of the real influence of a determined program, which might otherwise appear contradictory or even a "failure." 59 Similarly, complexity theory holds potential for understanding the dynamics of change and the multi-dimensional impact of interventions. ${ }^{60}$

Finally, the information contained in the study's database is useful for myriad purposes and in itself is a valuable source of information and analysis for researchers and program designers. Puntos' companion descriptive report, entitled Expectations and Realities: Nicaraguan youth navigate gender, sexuality, HIV and more, summarizes some of the most compelling patterns that emerge from the data collected between 2003 and 2005. Disaggregated by gender, age, and location, the data provide a complex portrait of the sexual and reproductive realities among Nicaraguan youth. ${ }^{61}$ The data also complement other sources such as the forthcoming Guttmacher Institute monograph To Assure a Healthier Tomorrow in Central America: Protect the Sexual and Reproductive Health of Today's Youth, which summarizes and compares national Demographic and Health Survey data from four Central American countries. ${ }^{62}$

\footnotetext{
${ }^{59}$ For a critical reflection on this aspect, see Bradshaw, S., I. Solórzano, and A. Bank. 2007. "The changing nature of change: A feminist experience in communication for social change in Nicaragua", published in World Congress on Communication for Development: Lessons, Challenges, and the Way Forward. World Bank, FAO, Communication Initiative.

${ }^{60}$ See "What Complexity Science Teaches Us about Social Change" by Virginia Lacayo, published in Mazi, the magazine of the

Communication for Social Change Consortium. http://www.communicationforsocialchange.org/mazi-articles.php?id=.

${ }^{61}$ Available in English at www.puntos.org.ni/english.

${ }^{62}$ Remez, L., E. Prada, S. Singh, L. Rosero Bixby, and A. Bankole. 2008. Asegurar un Mañana Más Saludable en Centroamérica: Proteger

la Salud Sexual y Reproductiva de la Juventud de Hoy. New York: Guttmacher Institute.
} 


\section{References}

Bandura, A. 1977. Social Learning Theory. Englewood Cliffs, New Jersey: Prentice-Hall, Inc.

. 1986. Social Foundations of Thought and Action: A Social Cognitive Theory. Englewood Cliffs, New Jersey: Prentice-Hall, Inc.

Bertrand, J. T. and R. Anhang. 2006. "The effectiveness of mass media in changing HIV-related behaviour among young people in developing countries," World Health Organization Technical Report Series 938: 205-41.

Bertrand, J. T. et al. 2006. "Systematic review of the effectiveness of mass communication programs to change HIV-related behaviors in developing countries," Health Education Research 21(4): 567-97.

Brown, L. et al. 2001. "Interventions to reduce HIV stigma: What have we learned?," Horizons Report. Washington, DC: Population Council.

Cochrane Collaborative Review Group on HIV Infection and AIDS. 2004. "Evidence assessment: strategies for HIV prevention, treatment and care."

Cohen, Jon. 2006. “Overview: The overlooked epidemic,” Science 313(5786): 468-469.

Declaration of Commitment on HIV/AIDS. 2001. "Resolution S-26/2," adopted by the General Assembly. http://www.un.org/ga/aids/coverage/FinalDeclarationHIVAIDS.html, retrieved Jan 2007.

Figueroa, M.E. et al. 2002. "An integrated model for measuring the process and its outcomes," the Communication for Social Change Working Paper Series, No. 1. New York: Rockefeller Foundation.

Gray-Felder, D. and J. Dean. 1999. “Communication for social change: A position paper and conference report.” New York: Rockefeller Foundation.

Greenberg, J. 1996. in AIDS Education: Interventions in Multicultural Settings. Edited by Schenker, I. et al. New York: Plenum Press.

Green, E. C. et al. 2006. "Uganda's HIV prevention success: the role of sexual behavior change and the national response," AIDS and Behavior 10(4): 335-346.

INIDE. 2005. "8th population census and 4th housing census, Vol. V, municipalities." Managua: Nicaragua.

Jato, M. et al. 1999. "The impact of multimedia family planning promotion on the contraceptive behavior of women in Tanzania," International Family Planning Perspectives 25(2): 60-67.

Malcolm, A. et al. 1998. "HIV and AIDS-related stigmatization and discrimination: Its form and contexts," Critical Public Health 8(4): 347-370. 
National STI/HIV Program. 2003. Ministry of Health.

Nicaraguan Statistics and Census Institute (INEC). 2002. "Encuesta Nicaragüense de demografía y salud 2001." Managua: INEC/MINSA.

—. 2006. “Censo Nacional 2005.” Managua: INEC.

—. Undated. "Population projections for the period 2000-2005," consulted on August 26, 2006, http://www.inec.gob.ni/estadisticas/proyecciones/pob00_05.htm.

Nyblade, Laura and Kerry MacQuarrie. 2006. "Can we measure HIV related stigma and discrimination? Current knowledge about quantifying stigma in developing countries." Washington, DC: ICRW and Policy Project.

Papa, M.J. et al. 2000. "Entertainment-education and social change: An analysis of parasocial interaction, social learning, collective efficacy, and paradoxical communication," Journal of Communication 50(4): 31-55.

Pulerwitz, Julie and Gary Barker. 2007. "Measuring attitudes toward gender norms among young men in Brazil: development and psychometric evaluation of the GEM Scale," Men and Masculinities published online ahead of print, 18 May.

Pulerwitz, J., S. L. Gortmaker, and W. DeJong. 2000. "Measuring relationship power in HIV/STD research," Sex Roles 42(7/8).

Rock, Yerina. 2005. “Television, gender and change: the case of 'Sexto Sentido' television, an education-entertainment initiative in Nicaragua," Master's Thesis. Great Britain: Cambridge University.

Singhal, A. and E. M. Rogers. 1999. Entertainment-education: A communication strategy for social change. Mahwah, New Jersey: Lawrence Earlbaum Associates.

STI, HIV and AIDS Surveillance. 2006. Trends of the Epidemiological Situation of HIV and AIDS in Nicaragua 1987-2006. Managua, Nicaragua: Ministry of Health.

Stoneburner, R. et al. 2000. "Knowledge diffusion and the personalisation of risk as key indicators of behaviour change in Uganda compared to Southern Africa," presentation at the XIII International Conference on AIDS, Durban, South Africa, July 9-14.

Westoff, CF and G. Rodríguez. 1995. "The mass media and family planning in Kenya," International Family Planning Perspectives 21(1): 26-31 and 36. 


\title{
Appendix 1 Additional Credits
}

\author{
Panel study \\ Data base: Francisco Centeno, Bismark Rodríguez (UNAN-León) \\ Cartography: Santos Betancourt, Maylen Balladares Cardoza, Arlen Córdobas (UNAN-León)
}

Field work: Mariano Salazar Torres, Alfredo Robleto Ruiz, Maylen Balladares Cardoza, Carolina Salinas, Roilen Aguilar, Blanca Rocha, Yaoska Madrigal, Lenin Martínez, Idelva Madrigal, Adela Carolina Rivas, Marcio Jonathan Díaz, Bayardo José Lazo, Deyanira Raquel Dávila, Nacira Hernandez Rivas, Karla Paredes, Melida Hernández, Jose Adán Hernández, Marbely López Gutiérrez, Marlon Javier Gutiérrez, Shayra García, Francisco Martínez Hurtado, Thelma Rosa García, Yelba Robleto, Hazle Guillermo López, Lucrecia Aragón Álvarez, Marbely López Robleto, Martha Obregón, Royler Aguilar, Esneider Dávila Dávila, Luis Gónzalez Velásquez, Gloria Rocha Marín, Maritza Hernández Miranda, Martha Maria Díaz , Jacqueline Leiva Huete, Amilcar Armando Aguilar, Harrington Jareth Guerrero, Ademilton Ramírez Miranda, Rommel Antonio Duarte, Arlen Córdobas, Maria Lourdes Lazo, Iris María Caruz, Karen Lissette Alaniz, Nelson Gonzáles, Ligia Ruiz Rodríguez, Fátima López Moreno, Marlon Ernesto Pérez, Egda Narua Vanegas, Dania Bellisa Pineda, Anabel Ruiz Rugada, Lesli Guido Lazo, Sandra Guido Lazo, Osman Téllez Gonzáles, Aurelia Maura Obando, Rommel Espinoza, Arlen Torrez Fernández, Arles Rene Rodríguez, Zaida Rocha, Lenin Pérez, Durkis Oseguera, Norman Cordobas, Yara Díaz, Mauricio Castillo, Julio Rivera, Yomaris Flores, Griselda Olivas Herdocia, Elsa Avilés, Nora Huete, Lourdes Castillo, Gill Zelaya Pérez, Ernesto López, Magbis Sanchez Zelaya, Carlos Calderon Valdivia, Marlon Moncada, Dania Pineda Herrera, Yorling Moreno, Ana Karelia Zeledón, Freddy Martín Guido, Carlos Calderón Valdivia, Carlos Sotomayor Lanuza, Erick Rizo Morales, Maria Selva, Jessenia García, Oscar David Blandino, Maria Teresa Orozco, Luz Marina Delgado, Aida Luz Flores, Oscar Isacs Martinez, Belkis Vargas Corrales, Benita Bernandina Flores, Miguel Centeno Cárdenas, Eusébio Adolfo Berrios, Elizabet Vanessa Paguagua. Cindy Esmeralda Orozco, Benito Martinez Saenz, Maria Rosa Pérez, Waleska Lindo, Eduardo Toval, Martha Barcenas, Armando Camacho, Maria José Gabuardi, Edwin Almanza Herrera, Yaquelin Mayorga, Norman Ferrer Alvarado, Gioconda Alvarado, Benito Moreno, Maria Argeñal, Rene Lucia Delgado, Héctor Sánchez, Juan Manuel Lozano, Luís Benito Quintero, Maria Rojas, Maria Elena Espinoza, Maria Isabel Hernández, Luisa Urcuyo Pérez, Carlos Berrios, Héctor Chamorro, Luis Benito Quintero, Carlos Rubio.

\section{Qualitative evaluation}

\section{Qualitative 1}

Oswaldo Montoya (Head Researcher)

Camilo Antillón, Rosa Argentina Campos, Karime Ulloa

Support team: Carlos Avalos, Braulio Delgado, Wendy Gaitán

\section{Qualitative 2}

Camilo Antillón and Henry Espinoza (Head Researchers)

Karime Ulloa, Vanesa López, León Berrios

Support team: Claudia Espinoza Sánchez, Arlen Altamirano, Carlos Cruz Espinoza, Ivanova Sosa

\section{Qualitative 3}

Almachiara D'Angelo and Patrick Welsh (Head Researchers)

\section{Support for the Puntos de Encuentro Team}

Rubén Reyes, Sheila Vega, Charlie Weinberg, Sarah Bradshaw, Ana Criquillion, Margarita Quintanilla, Yerina Rock, Juritzia Cruz, Kristen Shelby, Administration and General Services team, and the entire Puntos collective, as everyone contributed in one way or another. 


\section{Appendix 2 \\ Organizations and Media Outlets Who Participated in Qualitative Studies}

\begin{tabular}{|c|c|c|c|}
\hline Estelí & Juigalpa & León & Puerto Cabezas \\
\hline \multicolumn{4}{|l|}{ Qualitative study \#1 } \\
\hline \multicolumn{4}{|l|}{ Civil society } \\
\hline $\begin{array}{l}\text { Desafíos } \\
\text { MILAVF } \\
\text { Red de Jóvenes } \\
\text { Club Juvenil Profamilia } \\
\text { Casa de la Mujer } \\
\text { Casa del Adolescente } \\
\text { Funarte }\end{array}$ & $\begin{array}{l}\text { Casa del Adolescente } \\
\text { Alcaldía } \\
\text { Aldea SOS } \\
\text { Profamilia }\end{array}$ & $\begin{array}{l}\text { CISAS } \\
\text { CARAS } \\
\text { IXCHEN } \\
\text { Movimiento } \\
\text { Comunal } \\
\text { Proyecto Las Tías } \\
\text { Los Pipitos } \\
\text { CCAN } \\
\text { Centro Escolar }\end{array}$ & $\begin{array}{l}\text { CEDEHCA } \\
\text { Clínica Bilwi } \\
\text { Movimiento de Mujeres Nidia } \\
\text { White } \\
\text { Comisión Antidrogas } \\
\text { Comisaría de la Mujer, Niñez } \\
\text { y Adolescencia-Policía } \\
\text { Nacional }\end{array}$ \\
\hline \multicolumn{4}{|l|}{ Communication media } \\
\hline Radio Estereo Mundo & $\begin{array}{l}\text { Radio Centro } \\
\text { Corresponsal de La Prensa }\end{array}$ & Radio La Cariñosa & \\
\hline \multicolumn{4}{|l|}{ Qualitative study \#3 } \\
\hline \multicolumn{4}{|l|}{ Civil society } \\
\hline $\begin{array}{l}\text { Proyecto Miriam } \\
\text { Instituto Mujer y } \\
\text { Comunidad } \\
\text { Red de Jóvenes de Estelí } \\
\text { Xiloném } \\
\text { Casa de la Adolescencia } \\
\text { Instituto San Francisco } \\
\text { Hermanos Maristas. } \\
\text { Instituto Herman } \\
\text { Gmeiner }\end{array}$ & $\begin{array}{l}\text { AMNLAE } \\
\text { ATC } \\
\text { Secretaría del Concejo } \\
\text { Municipal } \\
\text { Club de Jóvenes } \\
\text { Profamilia } \\
\text { Aldea SOS } \\
\text { UNAG } \\
\text { Plan Nicaragua-Unidad } \\
\text { de Proyecto Juigalpa—- } \\
\text { Chontales } \\
\text { Casa de la Niñez, } \\
\text { Adolescencia y Juventud }\end{array}$ & & $\begin{array}{l}\text { CEDEHCA } \\
\text { Tesis } \\
\text { Movimiento de Mujer "Nidia } \\
\text { White" } \\
\text { Comisión Anti Drogas } \\
\text { Clínica Bilwi } \\
\text { Comisión Regional de } \\
\text { Prevención del VIH/SIDA } \\
\text { (CORESIDA) } \\
\text { AJECIM-Iglesia Morava }\end{array}$ \\
\hline \multicolumn{4}{|c|}{ Government institutions } \\
\hline $\begin{array}{l}\text { MIFAMILIA } \\
\text { Clínica de Adolescentes } \\
\text {-MINSA }\end{array}$ & & & $\begin{array}{l}\text { Comisaría de la Mujer, Niñez } \\
\text { y Adolescencia-Policía } \\
\text { Nacional }\end{array}$ \\
\hline
\end{tabular}




\section{Coordinating bodies}

Comisión de la Niñez y

la Adolescencia

Casa de la Niñez

Comisión de la Niñez y

Adolescencia

Communication media

Estéreo Mundo

Canal 4

Radio Liberación

Radio Centro

Radio Centro

Radio Cumiche

Canal 16

Canal 17

Radio Amor

Radio Juvenil 


\section{Hgrizons}

Horizons is a global operations research program designed to:

- Identify and test potential strategies to improve HIV/AIDS prevention, care, and support programs and service delivery.

- Disseminate best practices and utilize findings with a view toward scaling up successful interventions.

\section{(2) Population Council}

Horizons is implemented by the Population Council in collaboration with

- International Center for Research on Women (ICRW)

- International HIV/AIDS Alliance

- PATH

- Tulane University

- Family Health International (FHI)

- Johns Hopkins University

For more information, please contact:

Horizons Program, Communications Unit 4301 Connecticut Avenue, NW Suite 280 Washington, DC 20008 USA

Tel: 202-237-9400

Fax: 202-237-8410

Email: horizons@popcouncil.org

www.popcouncil.org/horizons 